Al Haidari, Afr J Tradit Complement Altern Med., (2018) 15 (3): 1-17

https://doi.org/10.21010/ajtcam.v15i3.1

\title{
A REVIEW OF TRADITIONAL USES, PHYTOCHEMICALS AND BIOACTIVITIES OF THE GENUS HYPOESTES
}

\author{
Rwaida A. Al Haidari \\ Department of Pharmacognosy and Pharmaceutical Chemistry, College of Pharmacy, Taibah University, Al \\ Madinah Al Munawwarah 41477, Saudi Arabia.
}

*Corresponding Author's E-mail: Rwaida s@yahoo.com

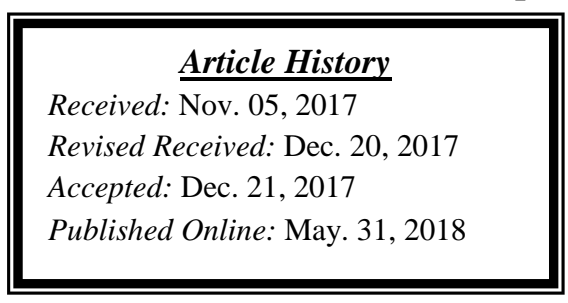

\begin{abstract}
Background: Plants have been used as a folkloric source of medicinal agents since the beginning of mankind. The genus Hypoestes (family Acanthaceae) includes over 150 species. The ethno-pharmacological studies of the plant belonging to this genus indicated that they possess various bioactivities as cytotoxic, anti-leismanial, antimicrobial, antimalarial, antioxidant, and anti-trypanosomal. Furthermore, they have been utilized in different traditional medicines for treating various aliments as eye sores, breast, liver, heart, and skin diseases, respiratory infections, anemia, malaria, scabies, typhoid, hypertension, and gonorrhea. This review focuses on the traditional uses, chemical constituents, and bioactivities of Hypoestes species.

Methods: The information was acquired from a literature searching in electronic databases such as ScienceDirect, PubMed, Google-Scholar, SpringerLink, Scopus, and Wiley up to 2017 for publications on genus Hypoestes.

Results: The genus Hypoestes had varied classes of chemical constituents, including diterpenoids, alkaloids, lignans, and pentacyclic triterpenes. Herein, 46 metabolites and more than 30 references have been cited.

Conclusion: This works provides a background for the future studies on Hypoestes species, particularly the species, which have not been extensively explored for separation and characterization of bioactive constituents and pharmacological potentials.
\end{abstract}

Keywords: Hypoestes, Acanthaceae, Uses, Chemical constituents, Biological activities.

List of abbreviations: ATCC: American Type Culture Collection; B16: Mouse melanoma; CAM: Chick chorioallantoic membrane; $\mathrm{CCl}_{4}$ : Carbon tetrachloride; $\mathrm{B} 16 \mathrm{~F} 1$ : Mouse melanoma cells; CA46: Human Burkitt lymphoma; Conc: Concentration; CCRF-CEM: Drug sensitive T-lymphoblastoid; CEM/ADR5000: Multidrug-resistant T-lymphoblastoid; DNA: Deoxyribonucleic acid; ED 50 : Effective dose; 5-FU: 5-fluorouracil; GOT: Glutamyl oxalacetate transaminases; GPT: Glutamate pyruvate transaminase; HEB4: Human normal melanocyte; HELA: cervical epitheloid carcinoma; HEPG2: Hepatocellular carcinoma; $\mathrm{IC}_{50}$ : The half maximal inhibitory concentration; IKK: kappa-B kinase subunit alpha; IZD: Inhibition zone diameter; IL: Interleukin; ILS: Increase in life spans; KB: Human epidermoid carcinoma cell; $\mathrm{KCl}$ : Potassium chloride; LPS: lipopolysaccharide; $\mathrm{MCF}_{7}$ : Human breast cancer; MIC: Minimum inhibitory concentration; $\mathrm{MRC}_{5}$ : Diploid human cell line; MTT: 3-(4,5-Dimethylthiazol-2-yl)-2,5diphenyltetrazolium bromide; P-388: Murine lymphocytic leukemia: Leukemia; PCV: Packed cell volume; RBC: Red blood cells-Erythrocytes; RNA: Ribonucleic acid; RSA: Radical scavenging activity; SD $_{90}$ : Suppressive dose 90; STM: Survival times mean; TLC: Thin layer chromatography.

\section{Introduction}

Plants have been used as a folkloric source of medicinal agents since the beginning of mankind. Despite major scientific progress in chemistry, drugs derived from plants still make an enormous contribution to drug discovery today and continue to be an important source to fight serious diseases as cancer, inflammation and bacterial and viral infections, especially in the developing countries (Zhang, 2004). Acanthaceae family is a tropical family consisting of $\approx$ two hundreds fifty genera and two thousands five hundreds species all over the world (Scotland and Vollesen, 2000). It is found in subtropical and tropical regions as Africa, Indo-Malaysia, Central America, and Brazil. It includes mainly perennial and annual herbs, climbers, and shrubs, as well as large trees. Hypoestes Soland. Ex R. Br. is one of the most important genera belonging to this family. Its generic name was attributed to both authors Robert Brown and Solander. Hypoestes is confined to the palaeotropics and subtropics, ranging from tropical Africa to Australia (Darbyshire, 2015). 
The plants of this genus are present in Asia, Australia, East Indies, and Africa. This genus can be distinguished from other Acanthaceae`s genus by the inelastic bases of placenta and union of the monothecous anthers with resupinate corollas. It contains over 150 species, $\approx 40-100$ of them are accepted (The Plantlist. 2013; Mabberley, 2008; Dyer, 1975) (Table 1).

Table 1: List of the accepted Hypoestes species (The Plant List, 2013)

\begin{tabular}{|c|c|c|}
\hline Species name & Species name & Species name \\
\hline H. acuminata Baker & H. fascicularis Nees & H. phyllostachya Baker \\
\hline H. angusta Benoist & H. flavescens Benoist & H. poissonii Benoist \\
\hline H. angustilabiata Benoist & H. flavovirens Benoist & H. potamophila Heine \\
\hline H. anisophylla Nees & H. flexibilis Nees & H. pulchra Nees \\
\hline H. arachnopus Benoist & H. forsskaolii (Vahl) R.Br. & H. purpurea (L.) R. Br. \\
\hline H. aristata (Vahl) Roem. \& Schult. & H. glandulifera Scott-Elliot & H. richardii Nees \\
\hline H. axillaris Benoist & $\begin{array}{l}\text { H. glandulosa (S. Moore) } \\
\text { Benoist }\end{array}$ & H. rodriguesiana Balf.f. \\
\hline H. bakeri Vatke & H. gracilis Nees & H. saboureaui Benoist \\
\hline H. barteri T. Anderson & H. hastata Benoist & $\begin{array}{l}\text { H. sanguinolenta (Van Houtte) } \\
\text { Hook. f. }\end{array}$ \\
\hline H. betsiliensis S. Moore & H. hirsuta Nees & H. saxicola Nees \\
\hline H. bodinieri H. Lév. & H. humbertii Benoist & H. scoparia Benoist \\
\hline H. bojeriana Nees & H. humifusa Benoist & H. secundiflora Baker \\
\hline H. bosseri Benoist & H. incompta Scott-Elliot & H. serpens R.Br. \\
\hline H. brachiata Baker & H. inconspicua Balf.f. & H. sessilifolia Baker \\
\hline H. calycina Benoist & H. isalensis Benoist & H. setigera Benoist \\
\hline H. cancellata Nees & H. jasminoides Baker & H. spicata Nees \\
\hline H. capitata Benoist & H. juanensis Benoist & H. stachyoides Baker \\
\hline H. catatii Benoist & H. laeta Benoist & H. stenoptera Benoist \\
\hline H. caudata Benoist & H. lasioclada Nees & H. taeniata Benoist \\
\hline H. cernua Nees & H. lasiostegia Nees & H. tetraptera Benoist \\
\hline H. chloroclada Baker & H. leptostegia S. Moore & H. teucrioides Nees \\
\hline $\begin{array}{l}\text { H. chlorotricha (Bojer ex Nees) } \\
\text { Benoist }\end{array}$ & H. longilabiata Scott-Elliot & H. teysmanniana Miq. \\
\hline H. cinerascens Benoist & H. longispica Benoist & H. thomsoniana Nees \\
\hline H. cochlearia Benoist & H. longituba Benoist & H. transversa Benoist \\
\hline H. comorensis Baker & H. loniceroides Baker & H. trichochlamys Baker \\
\hline H. comosa Benoist & H. macilenta Benoist & $\begin{array}{l}\text { H. triflora (Forssk.) Roem. \& } \\
\text { Schult. }\end{array}$ \\
\hline H. complanata Benoist & H. maculosa Nees & H. tubiflora Benoist \\
\hline H. congestiflora Baker & H. mangokiensis Benoist & H. unilateralis Baker \\
\hline H. consanguinea Lindau & H. mollissima (Vahl) Nees & H. urophora Benoist \\
\hline H. corymbosa Baker & H. multispicata Benoist & H. vagabunda Benoist \\
\hline H. cruenta Benoist & H. neesiana Kuntze & $\begin{array}{l}\text { H. verticillaris (L.f.) Sol. ex } \\
\text { Roem. \& Schult. }\end{array}$ \\
\hline $\begin{array}{l}\text { H. cumingiana (Nees) Benth. \& Hook. } \\
\text { f. }\end{array}$ & H. nummularifolia Baker & H. viguieri Benoist \\
\hline H. decaryana Benoist & H. obtusifolia Baker & H. warpurioides Benoist \\
\hline H. diclipteroides Nees & H. oppositiflora Benoist & H. phyllostachya Baker \\
\hline H. egena Benoist & H. oxystegia Nees & H. poissonii Benoist \\
\hline H. elegans Nees & H. parvula Benoist & H. potamophila Heine \\
\hline $\begin{array}{l}\text { H. elliotii S. Moore } \\
\text { H. erythrostachya Benoist }\end{array}$ & H. perrieri Benoist & H. pulchra Nees \\
\hline
\end{tabular}

Its species are distributed in various habitats: roadsides, woodland, dune and thick scrub, grassland, and forests. The taxonomical study of this genus has been carried out by Darbyshire et al. (2015). Hypoestes aristata Soland. ex Roem \& Schult., H. triflora (Forssk.) Roem. \& Schult., H. aristata (Vahl) Roem. \& Schult., H. verticillaris (L.f.) Roem. \& Schult., H. serpens (Vahl) R. Br., H. forskaolii (Vahl) R. Br., Hypoestes rosea P. Beauv, Hypoestes purpurea R. Br., H. phyllostachya "Rosea, and Hypoestes pubescens Balf.f are the commonly studied species of this genus. Members of this genus are commonly used in several countries traditional medicine all over the world for treating of various illness including, eye sores, breast, respiratory, skin, heart, and hepatic diseases, typhoid, anemia, gonorrhea, and malaria (Table 2). 
Table 2: List of some studied Hypoestes species and their traditional uses

\begin{tabular}{|c|c|c|}
\hline Species & Traditional uses & Ref \\
\hline $\begin{array}{l}\text { Hypoestes aristata Soland. } \\
\text { ex Roem and Schult. var. } \\
\text { aristata }\end{array}$ & $\begin{array}{l}\text { According to healers of the Xhosa tribe, the plant is } \\
\text { used to treat complicated diseases like cancer, arthritis, } \\
\text { tuberculosis, and bone fractures. } \\
\text { It has been used against eye sores, breast diseases, } \\
\text { respiratory infections, and malaria. }\end{array}$ & $\begin{array}{l}\text { Bhat, } 2014 \\
\text { Saeed et al. } 2016 \\
\text { Saeed et al. } 2016 \\
\text { Iwu, } 1993\end{array}$ \\
\hline $\begin{array}{l}\text { Hypoestes serpens (Vahl) } \\
\mathrm{R} . \mathrm{Br} .\end{array}$ & $\begin{array}{l}\text { In Malagasy folk medicine, it is used to treat high blood } \\
\text { pressure and infectious vaginitis. } \\
\text { In Madagascar and Saudi Arabia, it is used to treat } \\
\text { heart disease and hypertension. }\end{array}$ & $\begin{array}{l}\text { Rasoamiaranjanahary et al. } \\
2003 b \\
\text { Wu et al. } 2016\end{array}$ \\
\hline $\begin{array}{l}\text { Hypoestes tiflora (Forskall } \\
\text { Roemer et Schultes }\end{array}$ & $\begin{array}{l}\text { In Rwanda, the leaves are used in native medicine to } \\
\text { treat hepatic and skin diseases and worms. } \\
\text { The juice of the leaves is also used by the Rwandese } \\
\text { children as red ink. } \\
\text { In Bangladesh, leaf juice is orally administered for } \\
\text { jaundice. } \\
\text { In Ethiopia, the leaves are used for anemia. }\end{array}$ & $\begin{array}{l}\text { Puyvelde et al. 1989; } \\
\text { Mukazayire et al., } 2011\end{array}$ \\
\hline $\begin{array}{l}\text { Hypoestes forskalei Sol ex } \\
\mathrm{R} . \mathrm{Br}\end{array}$ & $\begin{array}{l}\text { In East African folk medicine, it is utilized for treating } \\
\text { vomiting, headache, nausea, heartburn, and nightmare. } \\
\text { In Cameroon, it used for skin infections (macerate } \\
\text { whole plant and apply topically, twice a day) } \\
\text { In Ethiopia, it is used for babesia (crush whole plant, } \\
\text { mix with honey and eat). } \\
\text { In Ethiopia, it is used for anthrax (crush whole part of } \\
\text { H. forskaolii with the seeds of Lepidium sativum, and } \\
\text { roots of Solanum incanum, macerate, filter and drink } \\
\text { the fluid). } \\
\text { In Saudi and Yemeni traditional medicines: it is utilized } \\
\text { for treating fungal skin diseases, scabies, and itching. } \\
\text { In Madagascar and Saudi Arabia, it is used to treat } \\
\text { heart disease and hypertension. } \\
\text { Among the Marakwet, it is used as a pesticide. }\end{array}$ & $\begin{array}{l}\text { Mothana et al. 2009; 2014; } \\
2011 \\
\text { Wu et al. } 2016 \\
\text { Kipkore et al. } 2014\end{array}$ \\
\hline Hypoestes rosea P. Beauv & $\begin{array}{l}\text { In Cameroon: it is used for typhoid (Infusion of plant } \\
\text { (whole plant, leaves and stems), } 1 \text { glass, } 4 \text { times a day). } \\
\text { The dried leaves powder is used for the management of } \\
\text { malaria by Nigerian natives. }\end{array}$ & $\begin{array}{l}\text { Fongod et al. } 2013 \\
\text { Ojo-Amaize et al. } 2007 \mathrm{~b}\end{array}$ \\
\hline $\begin{array}{l}\text { Hypoestes verticillaris } \\
\text { (L.f.) Sol. ex Roem. \& } \\
\text { Schult. }\end{array}$ & $\begin{array}{l}\text { In Kenya: it is used for treating tuberculosis, chest } \\
\text { complaints, dry cough, pneumonia, and wound healing, } \\
\text { also used as pesticide. } \\
\text { In Madagascar and Saudi Arabia, it is used in treating } \\
\text { hypertension and chest and heart diseases, gonorrhea, } \\
\text { and cancer. }\end{array}$ & $\begin{array}{l}\text { Al-Rehaily et al. 2002; Wu } \\
\text { et al. } 2016\end{array}$ \\
\hline es purpurea $\mathrm{R} . \mathrm{Br}$. & $\begin{array}{l}\text { In Taiwanese folk medicine, it is used as an anti- } \\
\text { phlogistic, antipyretic, and liver protective agent. }\end{array}$ & Shen et al. 2004 \\
\hline $\begin{array}{l}\text { Hypoestes pubescens } \\
\text { Balf.f }\end{array}$ & $\begin{array}{l}\text { It is utilized for treating fungal skin diseases and } \\
\text { scabies }\end{array}$ & Mothana et al. 2009 \\
\hline
\end{tabular}

They possessed varied bioactivities as anti-inflammatory, antifungal, anti-leishmanial, antitumor, antibacterial, anti-trypanosomal, antimalarial, and vasorelaxant. Surveying the literatures revealed that no review available is on this genus regarding the chemical constituents and bioactivities. Hence, the main goal of this review is to highlight the traditional uses, various metabolites and their occurrence, and bioactivities reported for this genus species (Tables $3 \&$ 4, Fig. 1-6). Also, it is aiming to supply knowledge to researchers for rapid identification of chemical constituents and pharmacological activities of Hypoestes genus plants. It can be utilized to validate the bioactivities and ethnomedicinal practices of this genus. 


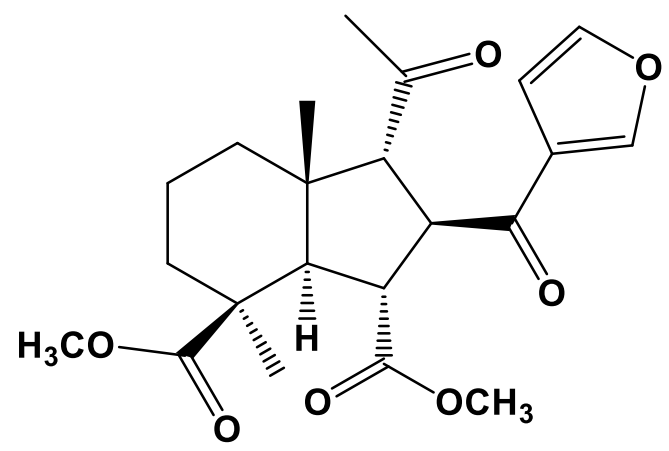

Hypophyllin A (1)
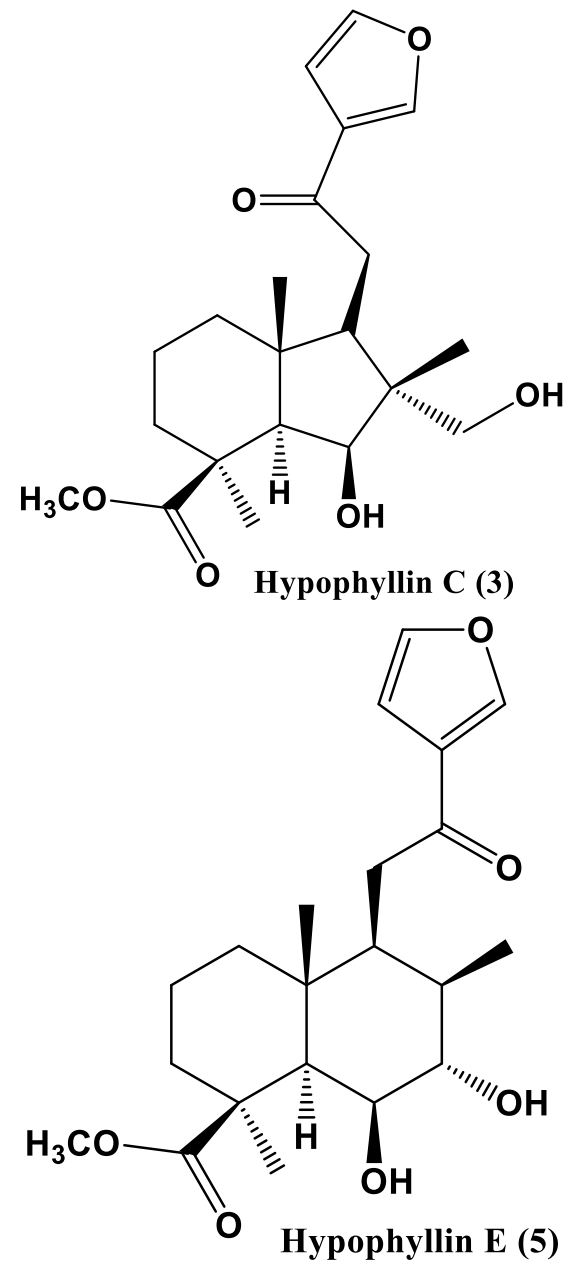
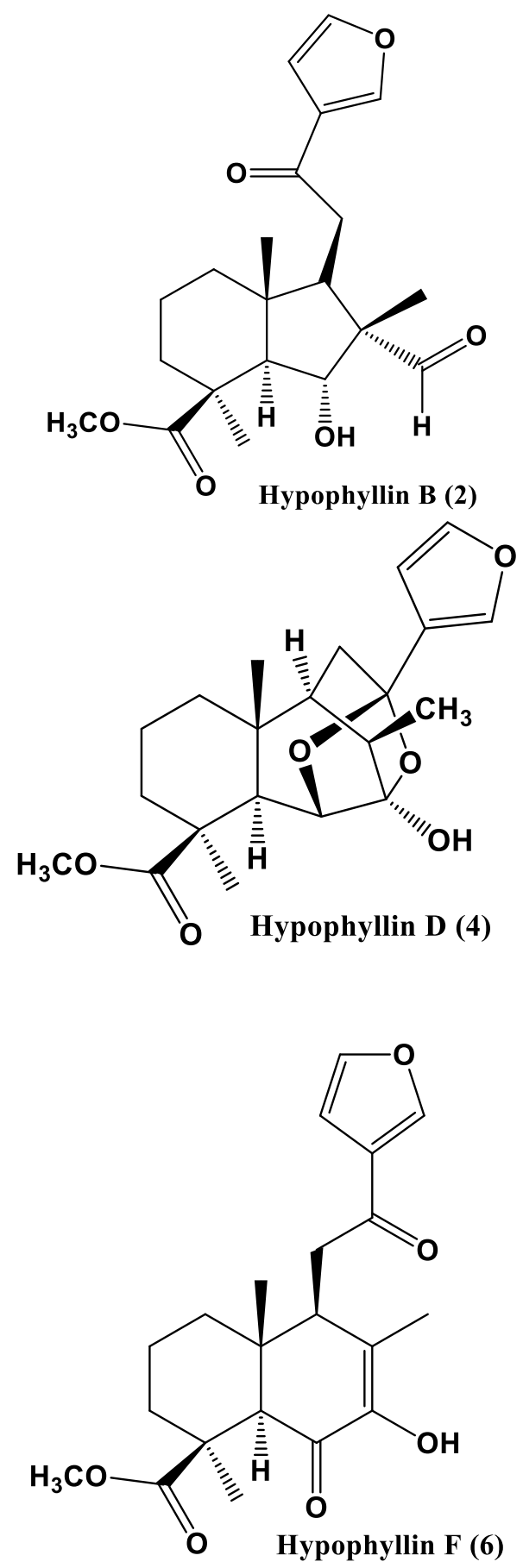

Figure 1: Chemical structures of compounds 1-6 


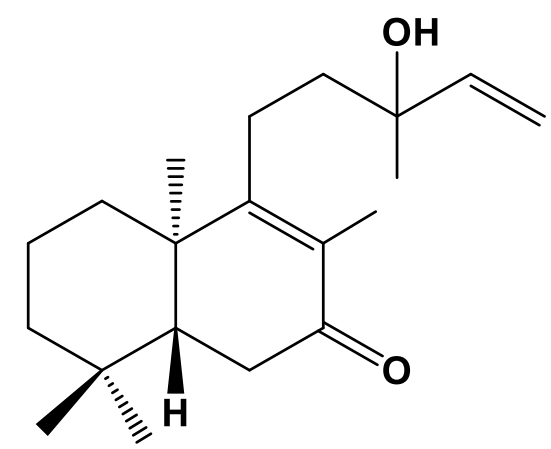

13-Hydroxy-7-oxo-labda-8-14-diene (7)
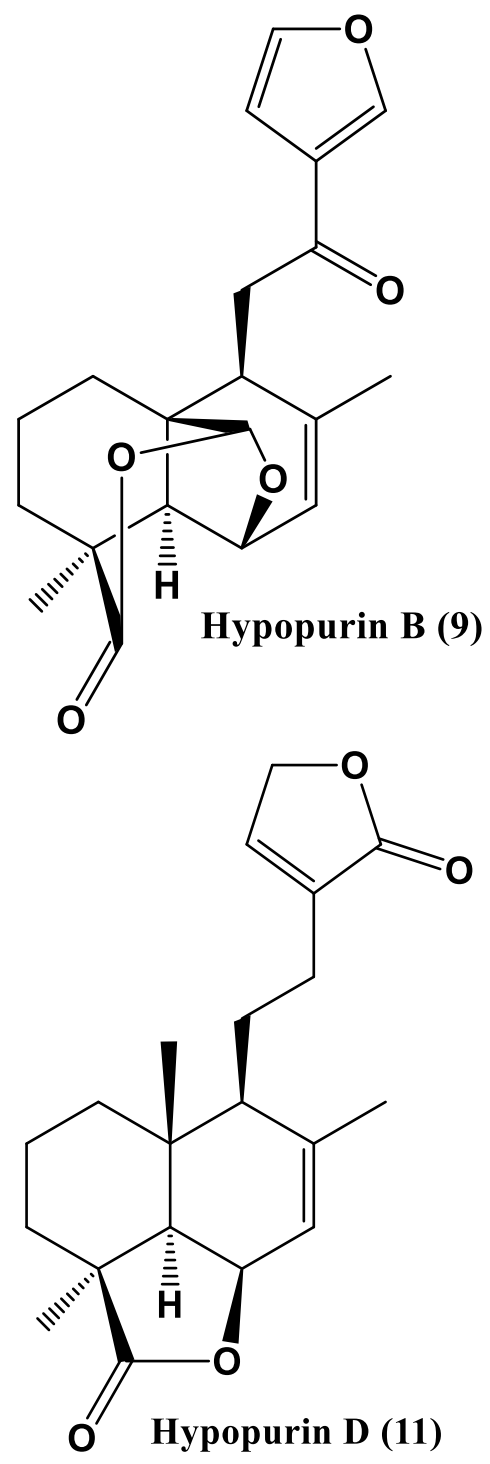
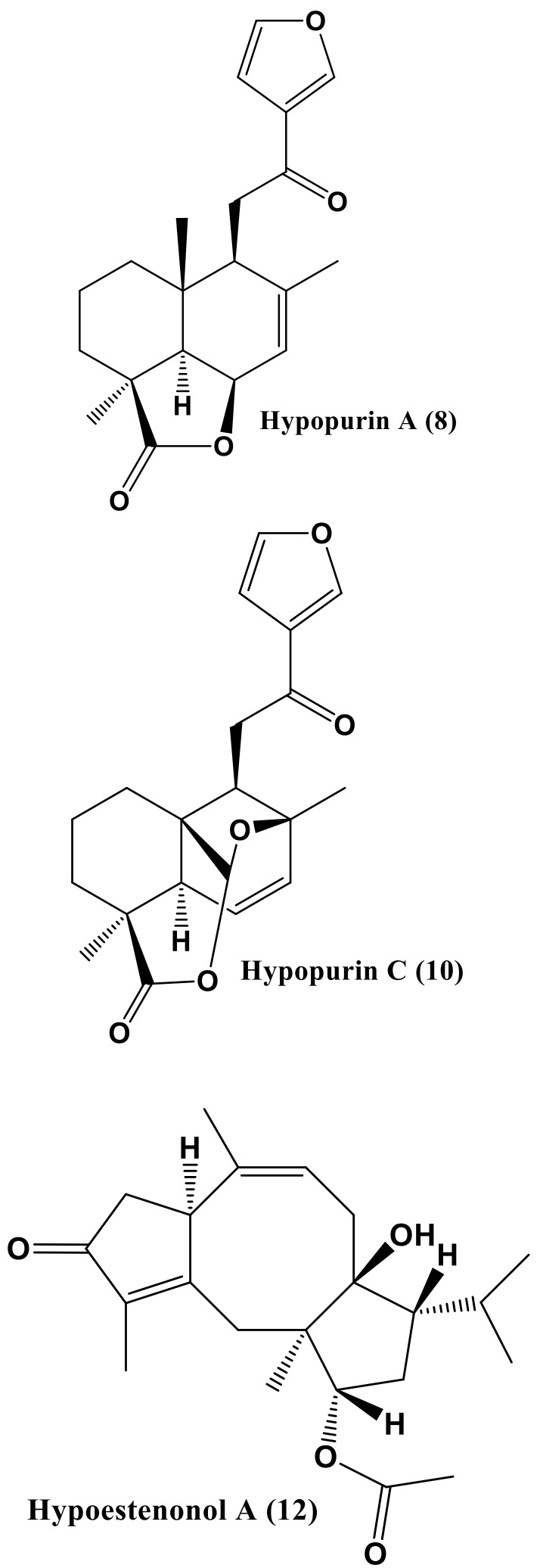

Figure 2: Chemical structures of compounds 7-12 
Table 3: List of compounds isolated from genus Hypoestes

\begin{tabular}{|c|c|c|c|c|}
\hline Compound name & Source & $\begin{array}{l}\text { Mol. } \\
\text { Formula } \\
\end{array}$ & $\begin{array}{l}\text { Mol. } \\
\text { Weight }\end{array}$ & Reference \\
\hline \multicolumn{5}{|l|}{ Diterpenoids: } \\
\hline \multicolumn{5}{|l|}{ A- Labdane-type: } \\
\hline Hypophyllin A (1) & $\begin{array}{l}\text { H. phyllostachya “Rosea“ } \\
\text { Baker J. Linn., whole plant }\end{array}$ & $\mathrm{C}_{22} \mathrm{H}_{28} \mathrm{O}_{7}$ & 404 & Wu et al., 2016 \\
\hline Hypophyllin B (2) & $\begin{array}{l}\text { H. phyllostachya "Rosea“ } \\
\text { whole plant }\end{array}$ & $\mathrm{C}_{21} \mathrm{H}_{28} \mathrm{O}_{6}$ & 376 & Wu et al., 2016 \\
\hline Hypophyllin C (3) & $\begin{array}{l}\text { H. phyllostachya “Rosea”, } \\
\text { whole plant }\end{array}$ & $\mathrm{C}_{21} \mathrm{H}_{30} \mathrm{O}_{6}$ & 378 & Wu et al., 2016 \\
\hline Hypophyllin D (4) & $\begin{array}{l}\text { H. phyllostachya 'Rosea”, } \\
\text { whole plant }\end{array}$ & $\mathrm{C}_{21} \mathrm{H}_{28} \mathrm{O}_{6}$ & 376 & Wu et al., 2016 \\
\hline Hypophyllin E (5) & $\begin{array}{l}\text { H. phyllostachya “Rosea”, } \\
\text { whole plant }\end{array}$ & $\mathrm{C}_{21} \mathrm{H}_{30} \mathrm{O}_{6}$ & 378 & Wu et al., 2016 \\
\hline Hypophyllin F (6) & $\begin{array}{l}\text { H. phyllostachya “'Rosea”, } \\
\text { whole plant }\end{array}$ & $\mathrm{C}_{21} \mathrm{H}_{26} \mathrm{O}_{6}$ & 374 & Wu et al., 2016 \\
\hline $\begin{array}{l}\text { 13-Hydroxy-7-oxo-labda-8- } \\
\text { 14-diene (7) }\end{array}$ & H. verticillaris, aerial parts & $\mathrm{C}_{20} \mathrm{H}_{32} \mathrm{O}_{2}$ & 304 & $\begin{array}{l}\text { Al-Rehaily et al., } \\
2002\end{array}$ \\
\hline \multicolumn{5}{|l|}{ B- Furanolabdane-type: } \\
\hline Hypopurin A (8) & $\begin{array}{l}\text { H. purpurea (L.) R. Br. } \\
\text { aerial parts }\end{array}$ & $\mathrm{C}_{20} \mathrm{H}_{24} \mathrm{O}_{4}$ & 328 & Shen et al., 2004 \\
\hline Hypopurin B (9) & H. purpurea, aerial parts & $\mathrm{C}_{20} \mathrm{H}_{22} \mathrm{O}_{5}$ & 342 & Shen et al., 2004 \\
\hline Hypopurin C (10) & H. purpurea, aerial parts & $\mathrm{C}_{20} \mathrm{H}_{22} \mathrm{O}_{5}$ & 342 & Shen et al., 2004 \\
\hline Hypopurin D (11) & H. purpurea, aerial parts & $\mathrm{C}_{20} \mathrm{H}_{26} \mathrm{O}_{4}$ & 330 & Shen et al., 2004 \\
\hline \multicolumn{5}{|l|}{ C- Fusicoccanes-type: } \\
\hline Hypoestenonol A (12) & $\begin{array}{l}\text { H. forskalei, (Vahl) Sol. ex } \\
\text { Roem. \& Schult., aerial parts }\end{array}$ & $\mathrm{C}_{22} \mathrm{H}_{32} \mathrm{O}_{4}$ & 360 & $\begin{array}{l}\text { Al Musayeib et al., } \\
2014\end{array}$ \\
\hline Hypoestenonol B (13) & H. forskalei, aerial parts & $\mathrm{C}_{22} \mathrm{H}_{32} \mathrm{O}_{4}$ & 360 & $\begin{array}{l}\text { Al Musayeib et al., } \\
2014\end{array}$ \\
\hline Verticillarone (14) & H. forskalei, aerial parts & $\mathrm{C}_{20} \mathrm{H}_{26} \mathrm{O}_{5}$ & 346 & $\begin{array}{l}\text { Al Musayeib et al., } \\
2014\end{array}$ \\
\hline & $\begin{array}{l}\text { H. verticillaris (L. f.) Sol. ex } \\
\text { Roem. \& Schult., aerial parts }\end{array}$ & & & $\begin{array}{l}\text { Al-Rehaily et al., } \\
2002\end{array}$ \\
\hline Hypoestenone (15) & H. forskalei, aerial parts & $\mathrm{C}_{20} \mathrm{H}_{28} \mathrm{O}_{2}$ & 300 & $\begin{array}{l}\text { Al Musayeib et al., } \\
2014\end{array}$ \\
\hline & H. forskalei, aerial parts & & & $\begin{array}{l}\text { Muhammad et al. } \\
1997\end{array}$ \\
\hline Serpendione 1 (16) & $\begin{array}{l}\text { H. serpens, (Vahl) R. Br., } \\
\text { whole plant }\end{array}$ & $\mathrm{C}_{21} \mathrm{H}_{26} \mathrm{O}_{4}$ & 342 & $\begin{array}{l}\text { Andriamihaja et al., } \\
2001\end{array}$ \\
\hline Roseadione (17) & H. rosea, leaves and twigs & $\mathrm{C}_{20} \mathrm{H}_{30} \mathrm{O}_{3}$ & 318 & $\begin{array}{l}\text { Adesomoju et al., } \\
\text { 1983b }\end{array}$ \\
\hline Deoxyhypoestenone (18) & H. forskalei, aerial parts & $\mathrm{C}_{20} \mathrm{H}_{30} \mathrm{O}$ & 286 & $\begin{array}{l}\text { Muhammad et al. } \\
1998\end{array}$ \\
\hline Dehydrohypoestenone (19) & H. forskalei, aerial parts & $\mathrm{C}_{20} \mathrm{H}_{26} \mathrm{O}_{2}$ & 298 & $\begin{array}{l}\text { Muhammad et al. } \\
1998\end{array}$ \\
\hline Hypoestene (20) & H. forskalei, aerial parts & $\mathrm{C}_{21} \mathrm{H}_{28} \mathrm{O}_{4}$ & 344 & $\begin{array}{l}\text { Muhammad et al. } \\
1998\end{array}$ \\
\hline Fusicoplagin D (21) & H. forskalei, aerial parts & $\mathrm{C}_{22} \mathrm{H}_{32} \mathrm{O}_{6}$ & 392 & $\begin{array}{l}\text { Muhammad et al. } \\
1998\end{array}$ \\
\hline $\begin{array}{l}(8) 9-\alpha- \\
\text { Epoxydeoxyhypoestenone } \\
(\mathbf{2 2})\end{array}$ & H. forskalei, aerial parts & $\mathrm{C}_{21} \mathrm{H}_{30} \mathrm{O}_{2}$ & 314 & $\begin{array}{l}\text { Muhammad et al. } \\
1998\end{array}$ \\
\hline $\begin{array}{l}\text { (8)9- } \alpha- \\
\text { Epoxyhypoestenone }(\mathbf{2 3})\end{array}$ & H. forskalei, aerial parts & $\mathrm{C}_{20} \mathrm{H}_{28} \mathrm{O}_{3}$ & 316 & $\begin{array}{l}\text { Muhammad et al. } \\
1998\end{array}$ \\
\hline Roseanolone (24) & $\begin{array}{l}\text { H. rosea } \mathrm{P} \text {. Beauv., whole } \\
\text { plant }\end{array}$ & $\mathrm{C}_{20} \mathrm{H}_{30} \mathrm{O}_{3}$ & 318 & Okogun et al., 1982 \\
\hline Isoroseanolone (25) & $\begin{array}{l}\text { H. rosea } \mathrm{P} . \text { Beauv., whole } \\
\text { plant }\end{array}$ & $\mathrm{C}_{20} \mathrm{H}_{34} \mathrm{O}_{3}$ & 322 & Okogun et al., 1982 \\
\hline Fusicoserpenol A (26) & H. serpens, leaves & $\mathrm{C}_{20} \mathrm{H}_{34} \mathrm{O}_{2}$ & 306 & $\begin{array}{l}\text { Rasoamiaranjanahary } \\
\text { et al., } 2003 \mathrm{~b}\end{array}$ \\
\hline
\end{tabular}




\begin{tabular}{|c|c|c|c|c|}
\hline \multicolumn{5}{|l|}{ D- Isopimarane type: } \\
\hline $\begin{array}{l}\text { 7 } \beta \text {-Hydroxyisopimara-8,15- } \\
\text { dien-14-one (27) }\end{array}$ & H. serpens, leaves & $\mathrm{C}_{20} \mathrm{H}_{30} \mathrm{O}_{2}$ & 302 & $\begin{array}{l}\text { Rasoamiaranjanahary } \\
\text { et al., 2003a }\end{array}$ \\
\hline $\begin{array}{l}\text { 14 } \alpha \text {-Hydroxyisopimara- } \\
\text { 7,15-dien-1-one }(\mathbf{2 8})\end{array}$ & H. serpens, leaves & $\mathrm{C}_{20} \mathrm{H}_{30} \mathrm{O}_{2}$ & 302 & $\begin{array}{l}\text { Rasoamiaranjanahary } \\
\text { et al., 2003a }\end{array}$ \\
\hline $\begin{array}{l}1 \beta, 14 \alpha- \\
\text { Dihydroxyisopimara-7,15- } \\
\text { diene }(\mathbf{2 9})\end{array}$ & H. serpens, leaves & $\mathrm{C}_{20} \mathrm{H}_{32} \mathrm{O}_{2}$ & 304 & $\begin{array}{l}\text { Rasoamiaranjanahary } \\
\text { et al., 2003a }\end{array}$ \\
\hline $\begin{array}{l}\text { 7 } \beta \text {-Acetoxyisopimara- } \\
8(14), 15 \text {-dien-1-one (30) }\end{array}$ & H. serpens, leaves & $\mathrm{C}_{21} \mathrm{H}_{32} \mathrm{O}_{2}$ & 316 & $\begin{array}{l}\text { Rasoamiaranjanahary } \\
\text { et al., 2003a }\end{array}$ \\
\hline $\begin{array}{l}\text { 7 } \beta \text {-Hydroxyisopimara- } \\
8(14), 15 \text {-dien-1-one }(\mathbf{3 1})\end{array}$ & H. serpens, leaves & $\mathrm{C}_{20} \mathrm{H}_{30} \mathrm{O}_{2}$ & 302 & $\begin{array}{l}\text { Rasoamiaranjanahary } \\
\text { et al., 2003a }\end{array}$ \\
\hline \multicolumn{5}{|l|}{ E- Dolabellane type } \\
\hline $\begin{array}{l}\text { Dolabeserpenoic acid A } \\
\text { (32) }\end{array}$ & H. serpens, leaves & $\mathrm{C}_{20} \mathrm{H}_{32}$ & 272 & $\begin{array}{l}\text { Rasoamiaranjanahary } \\
\text { et al., 2003b }\end{array}$ \\
\hline \multicolumn{5}{|l|}{ E- Verticillane-type } \\
\hline Hypoestoxide (33) & H. rosea, leaves and twigs & $\mathrm{C}_{22} \mathrm{H}_{32} \mathrm{O}_{5}$ & 376 & $\begin{array}{l}\text { Adesomoju et al., } \\
\text { 1983a }\end{array}$ \\
\hline \multicolumn{5}{|l|}{ Alkaloids } \\
\hline Hypoestestatin 1 (34) & H. verticillaris, shrub & $\mathrm{C}_{23} \mathrm{H}_{27} \mathrm{NO}_{3}$ & 365 & Pettit et al., 1984 \\
\hline Hypoestestatin 2 (35) & H. verticillaris, shrub & $\mathrm{C}_{23} \mathrm{H}_{27} \mathrm{NO}_{4}$ & 381 & Pettit et al., 1984 \\
\hline \multicolumn{5}{|l|}{ Lignans } \\
\hline$\alpha$-O-methylcubebin (36) & H. purpurea, aerial parts & $\mathrm{C}_{20} \mathrm{H}_{20} \mathrm{O}_{6}$ & 356 & Shen et al., 2004 \\
\hline Hinoquinin (37) & H. purpurea, aerial parts & $\mathrm{C}_{20} \mathrm{H}_{18} \mathrm{O}_{6}$ & 354 & Shen et al., 2004 \\
\hline Helioxanthin (38) & H. purpurea, aerial parts & $\mathrm{C}_{20} \mathrm{H}_{12} \mathrm{O}_{6}$ & 348 & Shen et al., 2004 \\
\hline Justicidine E (39) & H. purpurea, aerial parts & $\mathrm{C}_{20} \mathrm{H}_{12} \mathrm{O}_{6}$ & 348 & Shen et al., 2004 \\
\hline Dehydroxycubebin (40) & H. purpurea, aerial parts & $\mathrm{C}_{20} \mathrm{H}_{20} \mathrm{O}_{5}$ & 340 & Shen et al., 2004 \\
\hline 7-Hydroxyhinokinin (41) & H. purpurea, aerial parts & $\mathrm{C}_{20} \mathrm{H}_{18} \mathrm{O}_{8}$ & 386 & Shen et al., 2004 \\
\hline (-)-Hibalactone (42) & H. purpurea, aerial parts & $\mathrm{C}_{20} \mathrm{H}_{16} \mathrm{O}_{6}$ & 352 & Shen et al., 2004 \\
\hline$(+)-S e s a m i n(43)$ & H. forskalei, aerial parts & $\mathrm{C}_{20} \mathrm{H}_{18} \mathrm{O}_{6}$ & 354 & $\begin{array}{l}\text { Muhammad et al. } \\
1997\end{array}$ \\
\hline \multicolumn{5}{|l|}{ Triterpenes } \\
\hline Lupeol (44) & $\begin{array}{l}\text { H. purpurea, aerial parts } \\
\text { H. rosea, whole plant }\end{array}$ & $\mathrm{C}_{30} \mathrm{H}_{50} \mathrm{O}$ & 426 & $\begin{array}{l}\text { Shen et al., } 2004 \\
\text { Okogun et al., } 1982\end{array}$ \\
\hline Betulin (45) & H. purpurea, aerial parts & $\mathrm{C}_{30} \mathrm{H}_{50} \mathrm{O}_{2}$ & 442 & Shen et al., 2004 \\
\hline \multicolumn{5}{|l|}{ Acids } \\
\hline Benzoic acid (46) & Hypoestes triflora, leaves & & & Puyvelde et al., 1989 \\
\hline
\end{tabular}

\section{Phytochemical studies}

Phytochemical investigations carried out on various Hypoestes species revealed the existence of different classes of phytochemicals, as diterpenoids (labdane-, furanolabadane-, fusicoccane-, isopimarane-, verticillane-, and dolabellane-types), alkaloids, lignans, and pentacyclic triterpenes (Table 3 and Fig. 1-6). This review gives an account about phytochemicals that have been separated from the genus. It would also assist further using of the plants of this genus. The list of the identified constituents and their chemical structures are depicted in table 3 and figures 1-6.

\section{Biological activities \\ Hypoestes forskalei}

Hypoestenonols A (12) and B (13), hypoestenone (15), and verticillarone (14) were isolated from the MeOH extract of the aerial parts of Hypoestes forskalei. The MeOH extract showed antimalarial potential against Plasmodium falciparum $\mathrm{K} 1$-strain with half maximal inhibitory concentration $\left(\mathrm{IC}_{50}\right) 8.8 \mu \mathrm{g} / \mathrm{mL}$, compared to chloroquine ( $\left.\mathrm{IC}_{50}\right) 0.3$ $\mu \mathrm{M}$ ). Also, it possessed antileishmanial effect towards $L$. infantum (half maximal inhibitory concentration $\mathrm{IC}_{50} 8.1$ $\mu \mathrm{g} / \mathrm{mL}$ ) in comparison to fungizon ( $\left.\mathrm{IC}_{50} 1.5 \mu \mathrm{M}\right)$. In addition, it exhibited anti-trypanosomal potential towards $T$. cruzi and $T$. bruce $i$ with $\mathrm{IC}_{50} \mathrm{~s} 9.1$ and $8.1 \mu \mathrm{g} / \mathrm{mL}$, respectively, compared to the positive controls benznidazol (IC $\left.{ }_{50} 2.4 \mu \mathrm{M}\right)$ and suramine $\left(\mathrm{IC}_{50} 0.03 \mu \mathrm{M}\right)$, respectively without cytotoxicity $\left(\mathrm{IC}_{50}>64 \mu \mathrm{g} / \mathrm{mL}\right)$ on diploid human cell line $\left(\mathrm{MRC}_{5}\right)$ ) in the fluorimetrical assay. A very weak in vitro antiplasmodial capacities were observed for hypoestenonol A (12) ( $\left.\mathrm{IC}_{50} 18.9 \mu \mathrm{M}\right)$, verticillarone $(\mathbf{1 4})\left(\mathrm{IC}_{50} 25.1 \mu \mathrm{M}\right)$, and hypoestenone (15) ( $\left.\mathrm{IC}_{50} 16.7 \mu \mathrm{M}\right)$, in comparison to chloroquine ( $\left.\mathrm{IC}_{50} 0.3 \mu \mathrm{M}\right)$ (Al Musayeib et al., 2014).

The cytotoxic activity of the $\mathrm{MeOH}$ extract of aerial parts of $H$. forskale $i$ was determined using three human cancer cell lines: breast cancer (MCF7), hepatocellular carcinoma (HEPG2), and cervix cancer (HELA) cells. In 
addition, the human normal melanocyte (HFB4) was used as normal nonmalignant cell, using sulforhodamine B colorimetric assay. The total $\mathrm{MeOH}$ extract showed cytotoxic activity against HFB4, HEPG2, and HELA with $\mathrm{IC}_{50} \mathrm{~S}$ 4.18, 29.9, and $16.3 \mu \mathrm{g} / \mathrm{mL}$, respectively compared to doxorubicin $\left(\mathrm{IC}_{50} \mathrm{~s} 3.96,4.90\right.$, and $3.63 \mu \mathrm{g} / \mathrm{mL}$, respectively) and negative results against MCF7 cell line. However, the petroleum ether fraction possessed activity against MCF7, HFB4, HEPG2, and HELA with $\mathrm{IC}_{50} \mathrm{~s} 10.30,20.30,13.30$, and $10.30 \mu \mathrm{g} / \mathrm{mL}$, respectively compared to doxorubicin ( $\mathrm{IC}_{50} \mathrm{~s} 4.50,3.96,4.90$, and $3.63 \mu \mathrm{g} / \mathrm{mL}$, respectively). The mother liquor also had moderate cytotoxic activity (IC ${ }_{50} \mathrm{~s}$ $15.80,22.30,20.60$, and $12.10 \mu \mathrm{g} / \mathrm{mL}$, respectively) towards the same cell lines. Moreover, the $\mathrm{CHCl}_{3}$ and $n$ - $\mathrm{BuOH}$ fractions exhibited more cytotoxic activity against the four cell lines with $\mathrm{IC}_{50} \mathrm{~s} 4.17,5.18,4.57$, and $3.56 \mu \mathrm{g} / \mathrm{mL}$, respectively for the $\mathrm{CHCl}_{3}$ fraction and $\mathrm{IC}_{50} \mathrm{~s} 4.17,5.59,4.98$, and $3.56 \mu \mathrm{g} / \mathrm{mL}$, respectively for the $n$-BuOH fraction (Almehdar et al., 2012).

Table 4: List of the most potent compounds isolated from genus Hypoestes

\begin{tabular}{|c|c|c|c|c|c|}
\hline Compound name & $\begin{array}{l}\text { Biological } \\
\text { activity }\end{array}$ & $\begin{array}{l}\text { Assay, } \\
\text { organism, or } \\
\text { cell line }\end{array}$ & $\begin{array}{l}\text { Biological } \\
\text { results }\end{array}$ & $\begin{array}{l}\text { Positive } \\
\text { control }\end{array}$ & Reference \\
\hline \multirow[t]{2}{*}{ Hypophyllin A (1) } & Vasorelaxant & $\begin{array}{l}\mathrm{KCl} \text { induced } \\
\text { pre-contraction } \\
\text { in rat aorta } \\
\text { rings }\end{array}$ & $\begin{array}{l}9.04 \\
\text { maximum } \\
\text { relaxant ratio } \\
(\%) \text { after } 30 \\
\text { min }\end{array}$ & $\begin{array}{l}\text { Nifedipine } \\
91.67 \\
\text { maximum } \\
\text { relaxant ratio } \\
(\%) \text { after } 30 \\
\text { min }\end{array}$ & Wu et al., 2016 \\
\hline & Vasorelaxant & & $\begin{array}{l}31.27 \\
\text { maximum } \\
\text { relaxant ratio } \\
(\%) \text { after } 1 \mathrm{~h}\end{array}$ & $\begin{array}{l}\text { Nifedipine } \\
92.78 \\
\text { maximum } \\
\text { relaxant ratio } \\
(\%) \text { after } 1 \mathrm{~h}\end{array}$ & Wu et al., 2016 \\
\hline \multirow[t]{2}{*}{ Hypophyllin D (4) } & Vasorelaxant & $\begin{array}{l}\mathrm{KCl} \text { induced } \\
\text { pre-contraction } \\
\text { in rat aorta } \\
\text { rings }\end{array}$ & $\begin{array}{l}34.26 \\
\text { maximum } \\
\text { relaxant ratio } \\
(\%) \text { after } 30 \\
\text { min }\end{array}$ & $\begin{array}{l}\text { Nifedipine } \\
91.67 \\
\text { maximum } \\
\text { relaxant ratio } \\
(\%) \text { after } 30 \\
\text { min }\end{array}$ & Wu et al., 2016 \\
\hline & Vasorelaxant & & $\begin{array}{l}64.28 \\
\text { maximum } \\
\text { relaxant ratio } \\
(\%) \text { after } 1 \mathrm{~h}\end{array}$ & $\begin{array}{l}\text { Nifedipine } \\
92.78 \\
\text { maximum } \\
\text { relaxant ratio } \\
(\%) \text { after } 1 \mathrm{~h}\end{array}$ & Wu et al., 2016 \\
\hline \multirow[t]{2}{*}{ Hypophyllin E (5) } & Vasorelaxant & $\begin{array}{l}\mathrm{KCl} \text { induced } \\
\text { pre-contraction } \\
\text { in rat aorta } \\
\text { rings }\end{array}$ & $\begin{array}{l}36.80 \\
\text { maximum } \\
\text { relaxant ratio } \\
(\%) \text { after } 30 \\
\text { min }\end{array}$ & $\begin{array}{l}\text { Nifedipine } \\
91.67 \\
\text { maximum } \\
\text { relaxant ratio } \\
(\%) \text { after } 30 \\
\text { min }\end{array}$ & Wu et al., 2016 \\
\hline & Vasorelaxant & & $\begin{array}{l}63.83 \\
\text { maximum } \\
\text { relaxant ratio } \\
(\%) \text { after } 1 \mathrm{~h}\end{array}$ & $\begin{array}{l}\text { Nifedipine } \\
92.78 \\
\text { maximum } \\
\text { relaxant ratio } \\
(\%) \text { after } 1 \mathrm{~h}\end{array}$ & Wu et al., 2016 \\
\hline \multirow[t]{2}{*}{ Hypophyllin F (6) } & Vasorelaxant & $\begin{array}{l}\mathrm{KCl} \text { induced } \\
\text { pre-contraction } \\
\text { in rat aorta } \\
\text { rings }\end{array}$ & $\begin{array}{l}14.54 \\
\text { maximum } \\
\text { relaxant ratio } \\
(\%) \text { after } 30 \\
\text { min }\end{array}$ & $\begin{array}{l}\text { Nifedipine } \\
91.67 \\
\text { maximum } \\
\text { relaxant ratio } \\
(\%) \text { after } 30 \\
\text { min }\end{array}$ & Wu et al., 2016 \\
\hline & & & $\begin{array}{l}34.77 \\
\text { maximum } \\
\text { relaxant ratio } \\
(\%) \text { after } 1 \mathrm{~h}\end{array}$ & $\begin{array}{l}\text { Nifedipine } \\
92.78 \\
\text { maximum } \\
\text { relaxant ratio } \\
(\%) \text { after } 1 \mathrm{~h}\end{array}$ & Wu et al., 2016 \\
\hline Hypopurin A (8) & Cytotoxic & $\begin{array}{l}\text { KB, } \\
\text { MTT assay }\end{array}$ & $9.4 \mu \mathrm{M}\left(\mathrm{IC}_{50}\right)$ & & Shen et al., 2004 \\
\hline Hypoestenonol A & Antimalarial & P. falciparum & $18.9 \mu \mathrm{M}$ & Chloroquine & Al Musayeib et \\
\hline
\end{tabular}




\begin{tabular}{|c|c|c|c|c|c|}
\hline (12) & & $\begin{array}{l}{ }^{3} \mathrm{H}- \\
\text { hypoxanthine } \\
\text { incorporation } \\
\text { assay }\end{array}$ & $\left(\mathrm{IC}_{50}\right)$ & $0.3 \mu \mathrm{M}\left(\mathrm{IC}_{50}\right)$ & al., 2014 \\
\hline Verticillarone (13) & Antimalarial & $\begin{array}{l}P \text {. falciparum } \\
{ }^{3} \mathrm{H}- \\
\text { hypoxanthine } \\
\text { incorporation } \\
\text { assay }\end{array}$ & $\begin{array}{l}25.1 \mu \mathrm{M} \\
\left(\mathrm{IC}_{50}\right)\end{array}$ & $\begin{array}{l}\text { Chloroquine } \\
0.3 \mu \mathrm{M}\left(\mathrm{IC}_{50}\right)\end{array}$ & $\begin{array}{l}\text { Al Musayeib et } \\
\text { al., } 2014\end{array}$ \\
\hline Hypoestenone (15) & Antimalarial & $\begin{array}{l}P \text {. falciparum } \\
{ }^{3} \mathrm{H}- \\
\text { hypoxanthine } \\
\text { incorporation } \\
\text { assay }\end{array}$ & $\begin{array}{l}16.7 \mu \mathrm{M} \\
\left(\mathrm{IC}_{50}\right)\end{array}$ & $\begin{array}{l}\text { Chloroquine } \\
0.3 \mu \mathrm{M}\left(\mathrm{IC}_{50}\right)\end{array}$ & $\begin{array}{l}\text { Al Musayeib et } \\
\text { al., } 2014\end{array}$ \\
\hline Serpendione 1 (16) & Vasorelaxant & $\begin{array}{l}\mathrm{KCl} \text { induced } \\
\text { pre-contraction } \\
\text { in rat aorta } \\
\text { rings }\end{array}$ & $\begin{array}{l}92.2 \\
\text { maxiumum } \\
\text { relaxant ratio } \\
(\%) \text { after } 30 \\
\text { min }\end{array}$ & $\begin{array}{l}\text { Nifedipine } \\
92.78 \\
\text { maxiumum } \\
\text { relaxant ratio } \\
(\%) \text { after } 1 \mathrm{~h}\end{array}$ & $\begin{array}{l}\text { Andriamihaja et } \\
\text { al., } 2001\end{array}$ \\
\hline $\begin{array}{l}\text { Fusicoserpenol A } \\
\text { (26) }\end{array}$ & Antifungal & $\begin{array}{l}\text { TLC } \\
\text { bioautographic } \\
\text { assay } \\
\text { Cladosporium } \\
\text { Cucumerunum } \\
\text { (ATCC No. } \\
\text { 16402) } \\
\text { Candida } \\
\text { albicans }\end{array}$ & $\begin{array}{l}2.0 \mu \mathrm{g} / \mathrm{TLC} \\
\text { plate }\end{array}$ & $\begin{array}{l}\text { Miconazole } \\
1.0 \mu \mathrm{g} / \mathrm{TLC} \\
\text { plate }\end{array}$ & $\begin{array}{l}\text { Rasoamiaranjanah } \\
\text { ary et al., } 2003 b\end{array}$ \\
\hline $\begin{array}{l}\text { 7ß- } \\
\text { Hydroxyisopimara- } \\
\text { 8,15-dien-14-one } \\
(\mathbf{2 7})\end{array}$ & Antifungal & $\begin{array}{l}\text { Cladosporium } \\
\text { Cucumerunum } \\
\text { (ATCC No. } \\
\text { 16402), TLC } \\
\text { bioautographic } \\
\text { assay } \\
\text { Candida } \\
\text { albicans, TLC } \\
\text { bioautographic } \\
\text { assay }\end{array}$ & $\begin{array}{l}1.0 \mu \mathrm{g} / \mathrm{TLC} \\
\text { plate }\end{array}$ & $\begin{array}{l}\text { Miconazole } \\
1.0 \mu \mathrm{g} / \mathrm{TLC} \\
\text { plate } \\
\\
\text { Miconazole } \\
1.0 \mu \mathrm{g} / \mathrm{TLC} \\
\text { plate }\end{array}$ & $\begin{array}{l}\text { Rasoamiaranjanah } \\
\text { ary et al., 2003a }\end{array}$ \\
\hline & $\begin{array}{l}\text { Acetylcholinestera } \\
\text { se } \\
\text { inhibitory }\end{array}$ & $\begin{array}{l}\text { TLC } \\
\text { bioautographic } \\
\text { assay }\end{array}$ & $\begin{array}{l}0.5 \mu \mathrm{g} / \mathrm{TLC} \\
\text { plate }\end{array}$ & $\begin{array}{l}\text { Galanthamine } \\
0.01 \mu \mathrm{g} / \mathrm{TLC} \\
\text { plate }\end{array}$ & \\
\hline $\begin{array}{l}14 \alpha- \\
\text { Hydroxyisopimara- } \\
7,15 \text {-dien-1-one }(\mathbf{2 8})\end{array}$ & $\begin{array}{l}\text { Acetylcholinestera } \\
\text { se } \\
\text { inhibitory }\end{array}$ & $\begin{array}{l}\text { Cladosporium } \\
\text { Cucumerunum } \\
\text { (ATCC No. } \\
\text { 16402), TLC } \\
\text { bioautographic } \\
\text { assay } \\
\text { Candida } \\
\text { albicans, TLC } \\
\text { bioautographic } \\
\text { assay } \\
\text { TLC } \\
\text { bioautographic } \\
\text { assay }\end{array}$ & $\begin{array}{l}1.0<\mu \mathrm{g} / \mathrm{TLC} \\
\text { plate } \\
0.2 \mu \mathrm{g} / \mathrm{TLC} \\
\text { plate }\end{array}$ & $\begin{array}{l}\text { Miconazole } \\
1.0 \mu \mathrm{g} / \mathrm{TLC} \\
\text { plate } \\
\text { Galanthamine } \\
0.01 \mu \mathrm{g} / \mathrm{TLC} \\
\text { plate }\end{array}$ & $\begin{array}{l}\text { Rasoamiaranjanah } \\
\text { ary et al., 2003a }\end{array}$ \\
\hline $\begin{array}{l}7 \beta- \\
\text { Acetoxyisopimara- } \\
8(14), 15 \text {-dien-1-one } \\
(\mathbf{3 0})\end{array}$ & Antifungal & $\begin{array}{l}\text { Cladosporium } \\
\text { Cucumerunum } \\
\text { (ATCC No. } \\
\text { 16402), } \\
\text { TLC } \\
\text { bioautographic } \\
\text { assay }\end{array}$ & $\begin{array}{l}1.0<\mu \mathrm{g} / \mathrm{TLC} \\
\text { plate }\end{array}$ & $\begin{array}{l}\text { Miconazole } \\
1.0 \mu \mathrm{g} / \mathrm{TLC} \\
\text { plate }\end{array}$ & $\begin{array}{l}\text { Rasoamiaranjanah } \\
\text { ary et al., 2003a }\end{array}$ \\
\hline
\end{tabular}




\begin{tabular}{|c|c|c|c|c|c|}
\hline & & $\begin{array}{l}\text { Candida } \\
\text { albicans }\end{array}$ & $\begin{array}{l}1.0<\mu \mathrm{g} / \mathrm{TLC} \\
\text { plate }\end{array}$ & $\begin{array}{l}\text { Miconazole } \\
1.0 \mu \mathrm{g} / \mathrm{TLC} \\
\text { plate }\end{array}$ & \\
\hline \multirow{4}{*}{$\begin{array}{l}\text { Dolabeserpenoic } \\
\text { acid A (32) }\end{array}$} & \multirow[t]{4}{*}{ Antifungal } & Cladosporium & & Miconazole & \multirow{4}{*}{$\begin{array}{l}\text { Rasoamiaranjanah } \\
\text { ary et al., 2003a }\end{array}$} \\
\hline & & $\begin{array}{l}\text { Cucumerunum } \\
\text { (ATCC No. }\end{array}$ & & $\begin{array}{l}1.0 \mu \mathrm{g} / \mathrm{TLC} \\
\text { plate }\end{array}$ & \\
\hline & & $\begin{array}{l}\text { 16402), TLC } \\
\text { bioautographic } \\
\text { assay }\end{array}$ & $\begin{array}{l}5 \mu \mathrm{g} / \mathrm{TLC} \\
\text { plate }\end{array}$ & & \\
\hline & & $\begin{array}{l}\text { Candida } \\
\text { albicans, TLC } \\
\text { bioautographic } \\
\text { assay }\end{array}$ & $\begin{array}{l}5 \mu \mathrm{g} / \mathrm{TLC} \\
\text { plate }\end{array}$ & $\begin{array}{l}\text { Miconazole } \\
1.0 \mu \mathrm{g} / \mathrm{TLC} \\
\text { plate }\end{array}$ & \\
\hline \multirow[t]{4}{*}{ Hypoestoxide (33) } & $\begin{array}{l}\text { Anti- } \\
\text { inflammatory }\end{array}$ & $\begin{array}{l}\text { Phorbol Ester- } \\
\text { Induced Topical } \\
\text { Inflammation }\end{array}$ & $\begin{array}{l}57 \% \\
\text { thickness } \\
\text { inhibition/ear }\end{array}$ & \multirow{4}{*}{$\begin{array}{l}\text { Dexamethason } \\
\text { e-21-acetate } \\
63 \% \text { thickness } \\
\text { inhibition/ear } \\
\text { rhIFN- } \alpha / \beta \\
100 \text { units } \\
55 \% \text { inhibition } \\
\text { of lung } \\
\text { colonization } \\
\text { Chloroquine } \\
0.11 \mu \mathrm{M}\left(\mathrm{IC}_{50}\right)\end{array}$} & $\begin{array}{l}\text { Ojo-Amaize et al., } \\
2001\end{array}$ \\
\hline & Cytotoxic & $\begin{array}{l}\text { B16F1 } \\
\text { in ovo chick }\end{array}$ & $\begin{array}{l}5.0 \mathrm{mg} / \mathrm{kg}- \\
66 \%\end{array}$ & & $\begin{array}{l}\text { Ojo-Amaize et al., } \\
2002\end{array}$ \\
\hline & & CAM assay & $\begin{array}{l}\text { inhibition of } \\
\text { lung } \\
\text { colonization }\end{array}$ & & \\
\hline & Antimalarial & $\begin{array}{l}P . \text { falciparum } \\
{ }^{3} \mathrm{H}- \\
\text { hypoxanthine } \\
\text { incorporation } \\
\text { assay }\end{array}$ & $10 \mu \mathrm{M}\left(\mathrm{IC}_{50}\right)$ & & $\begin{array}{l}\text { Ojo-Amaize et al., } \\
2007 \mathrm{~b}\end{array}$ \\
\hline $\begin{array}{l}\text { Hypoestestatin } 1 \\
\text { (34) }\end{array}$ & Cytotoxic & $\begin{array}{l}\text { P-388 cells, } \\
\text { MTT assay }\end{array}$ & $\begin{array}{l}10^{-5} \mu \mathrm{g} / \mathrm{mL} \\
\left(\mathrm{ED}_{50}\right)\end{array}$ & & Pettit et al., 1984 \\
\hline $\begin{array}{l}\text { Hypoestestatin } 2 \\
\text { (35) }\end{array}$ & Cytotoxic & $\begin{array}{l}\text { P-388 cells, } \\
\text { MTT assay }\end{array}$ & $\begin{array}{l}10^{-5} \mu \mathrm{g} / \mathrm{mL} \\
\left(\mathrm{ED}_{50}\right)\end{array}$ & & Pettit et al., 1984 \\
\hline
\end{tabular}

Mothana et al. (2014) (2011) reported that the aerial parts of $H$. forskalei extract exhibited antiprotozoal activity towards Leishmania infantum with $\mathrm{IC}_{50}$ of $8.1 \mu \mathrm{g} / \mathrm{mL}$ compared to miltefosine $\left(\mathrm{IC}_{50}\right.$ of $\left.3.32 \mu \mathrm{g} / \mathrm{mL}\right)$. It displayed antimalarial potential $\mathrm{IC}_{50}$ (of $8.8 \mu \mathrm{g} / \mathrm{mL}$ ) compared to chloroquine ( $\mathrm{IC}_{50}$ of $0.3 \mu \mathrm{g} / \mathrm{mL}$ ) towards chloroquinesensitive $P$. falciparum K1-strain. It had anti-trypanosomal potential towards T. brucei Squib-427 strain (suraminsensitive) with an $\mathrm{IC}_{50} 8.1 \mu \mathrm{g} / \mathrm{mL}$, compared to suramin $\left(\mathrm{IC}_{50} 0.03 \mu \mathrm{g} / \mathrm{mL}\right.$ ) and against $T$. cruzi Tulahuen CL2 (benznidazole-sensitive) with an $\mathrm{IC}_{50}$ of $9.1 \mu \mathrm{g} / \mathrm{mL}$, in comparison to beznidazole $\left(\mathrm{IC}_{50} 2.2 \mu \mathrm{g} / \mathrm{mL}\right.$ ). In addition, it had cytotoxic activity in resazurin fluorescent assay towards human lung fibroblast cell lines (MRC-5) with an $\mathrm{IC}_{50} 11.0$ $\mu \mathrm{g} / \mathrm{mL}$, compared to tamoxifen $\left(\mathrm{IC}_{50} 11.0 \mu \mathrm{g} / \mathrm{mL}\right.$ ) (Mothana et al., 2011; 2014). H. forskalei aerial parts extract was assessed for cytotoxic, antimicrobial, and antioxidant activities. The antimicrobial effect was carried out towards Staphylococcus aureus (ATCC 6538), Micrococcus flavus (SBUG 16), Bacillus subtilis (ATCC 6059), Pseudomonas aeruginosa (ATCC 27853), Escherichia coli (ATCC 11229), and Candida maltosa (SBUG) using agar diffusion and broth micro-dilution assays (Mothana et al., 2011). It possessed only antifungal potential (Conc. $4.0 \mathrm{mg} / \mathrm{disc}$ ) towards C. maltosa with inhibition zone diameter (IZD) $18 \mathrm{~mm}$, compared to amphotericin (Conc. $10 \mu \mathrm{g} / \mathrm{disc}$, IZD $11 \mathrm{~mm}$ ). Also, it had cytotoxic potential in microtiter plate assay towards human breast cancer (MCF-7) [ATCC HTB-22] and human urinary bladder carcinoma (5637) [ATCC HTB-9] cell lines with $\mathrm{IC}_{50} \mathrm{~s} 32.1$ and $14.3 \mu \mathrm{g} / \mathrm{mL}$, respectively compared to etoposide $\left(\mathrm{IC}_{50} \mathrm{~s} 5.62\right.$ and $2.27 \mu \mathrm{M}$, respectively). It showed potent concentration-dependent antioxidant potential with radical scavenging activity (RSA) 1.5, 14.8, 43.8, 96.5, and $94.7 \%$ (conc. 10, 50, 100, 500, and 1000 $\mu \mathrm{g} / \mathrm{mL}$, respectively), in comparison to ascorbic acid (RSA: 45.2, 97.1, 96.5, 97.6, and 96.3\%) at the same concentrations (Mothana et al., 2011). Muthaura et al. (2015) reported that $\mathrm{MeOH}$ of H. forskalei showed antimalarial activity against $P$. falciparum (D6 clone) with an $\mathrm{IC}_{50} 5.6 \mu \mathrm{g} / \mathrm{mL}$ in ${ }^{3} \mathrm{H}$-hypoxanthine incorporation assay (Muthaura et al., 2015). Ubaha et al. (2012) reported that the leaves and stem $\mathrm{H}_{2} \mathrm{O}$ extracts of $H$. forskalei possessed piscicidal potential towards Clarias gariepinus (African mud cat fish). The mortality diminished with reducing the extracts concentration at all treated fish's stages. The packed cell volume (PCV), concentration of hemoglobin, and count of red blood cells (RBC) of the treated fishes were noticeably decreased compared to the control. Thus, H. forskalei had high piscicidal and high toxic effects to the aquatic lives and could produce internal organs hazards on the fish consumers (Ubaha et al., 2012). 


\section{Hypoestes phyllostachya}

Wu et al. (2016) evaluated the vasorelaxant effects on endothelium-intact thoracic aorta rings pre-contracted with potassium chloride $(\mathrm{KCl})$ of hypophyllins A (1) and D-F (4-6) separated from aerial parts of $H$. phyllostachya (Wu et al., 2016). Hypophyllins A (1) and D-F (4-6) (Conc. $100 \mu \mathrm{M}$ ) exhibited potent vasorelaxant action with the maximum relaxant activity. Moreover, $\mathbf{4}$ and $\mathbf{5}$ showed a higher vasorelaxant effect than other compounds with the maximum relaxant ratios 64.28 and $63.83 \%$, respectively compared to nifedipine (maximum relaxant ratio $92.78 \%$ ). Whereas, 1 and $\mathbf{6}$ exhibited maximum relaxant values of 31.27 and $34.77 \%$, respectively (Wu et al., 2016). Interestingly, 4 possessed an uncommon 8,9-dioxatricyclic[4.2.1.13,7]decane skeleton, indicating that this cagedmoiety is possibly important for the vasorelaxant potential.
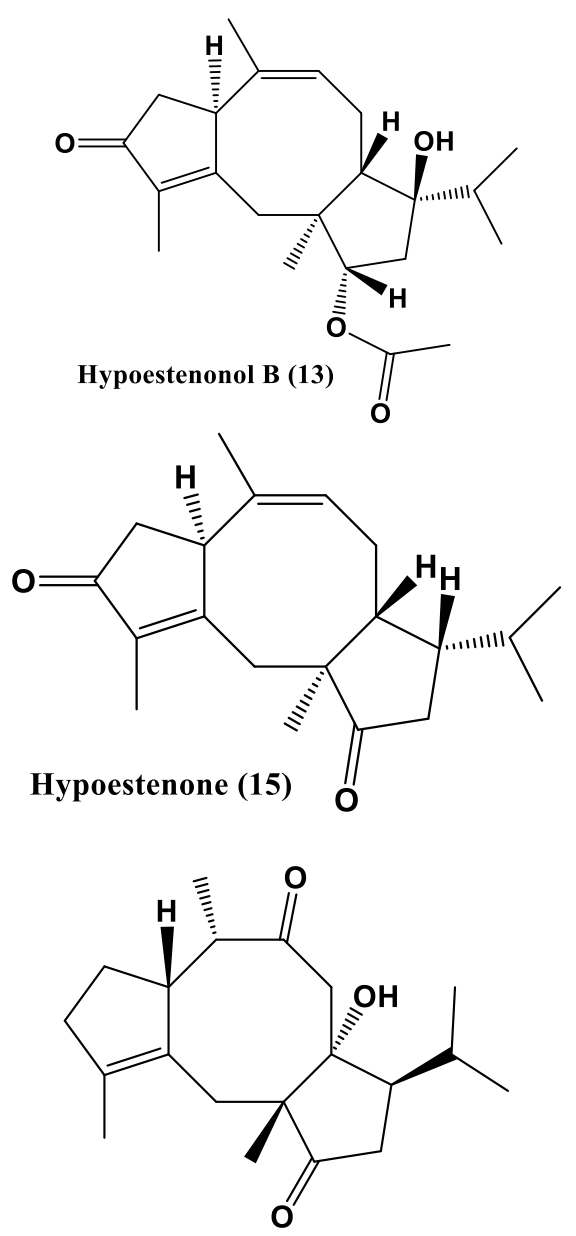

Roseadione (17)

(10-Hydroxy-2-fusicoccene-8,12-dione)

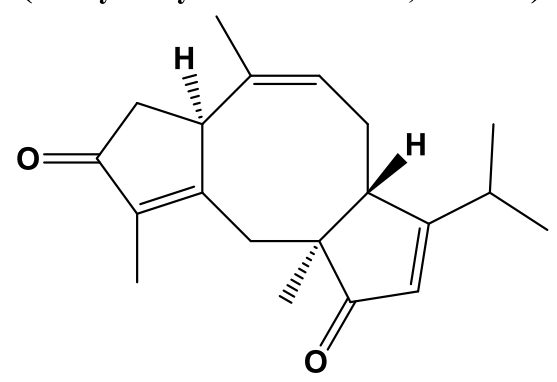

Dehydrohypoestenone (19)
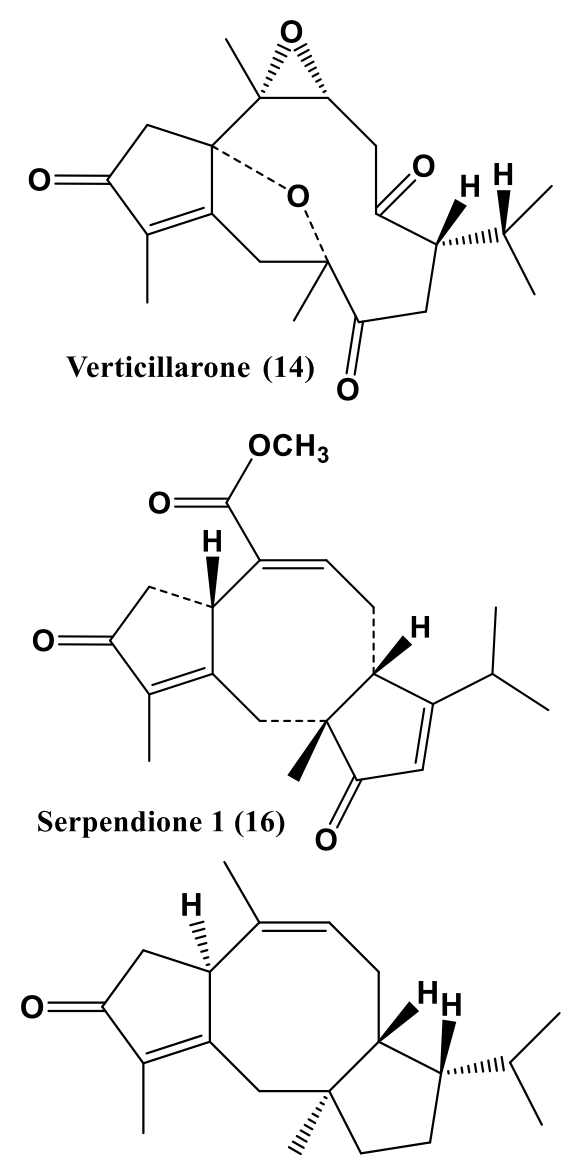

Deoxyhypoestenone (18)

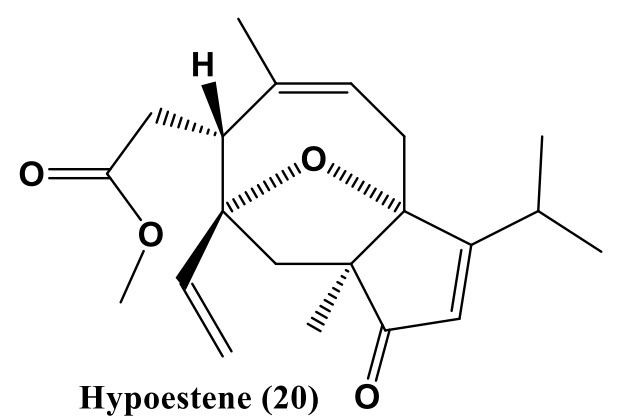

Figure 3: Chemical structures of compounds 13-20 

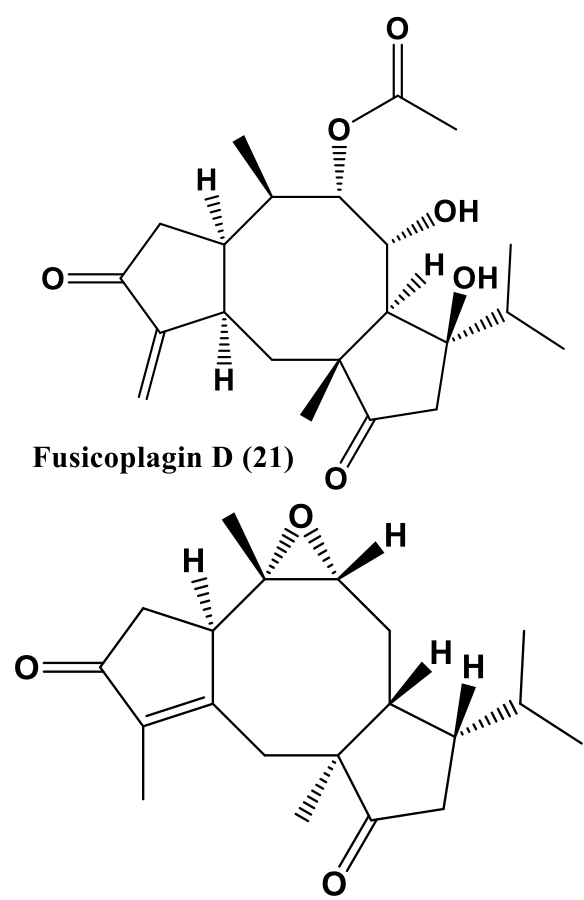

8(9)- $\alpha$-Epoxyhypoestenone (23)

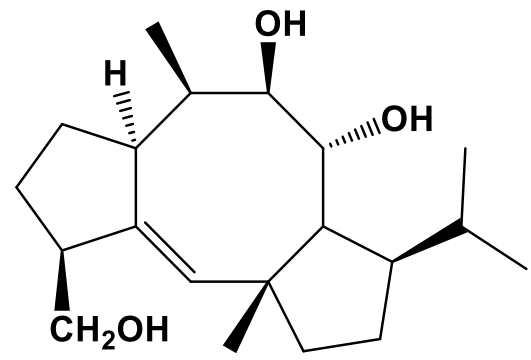

Isoroseanolone (25)

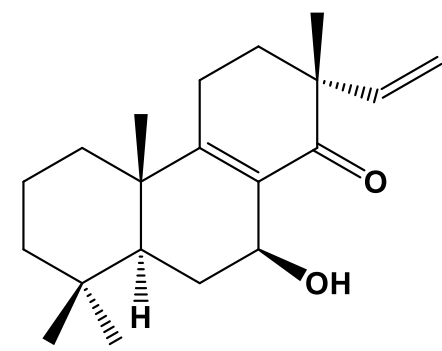

7ß-Hydroxyisopimara-8,15-dien-14-one (27)

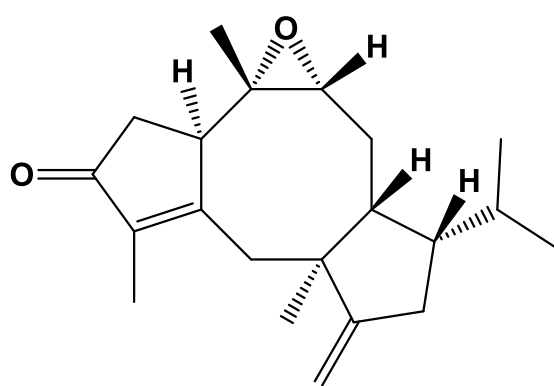

8(9)- $\alpha-$ Epoxydeoxyhypoestenone (22)
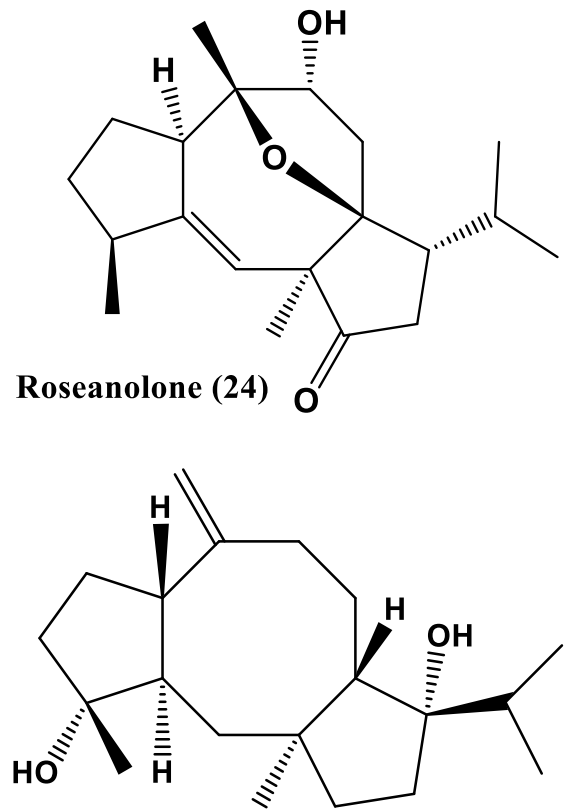

Fusicoserpenol A (26)

(4,12-Dihydroxy-8(17)-fusicoccene)<smiles>C=C[C@]1(C)CC[C@H]2C(=CC[C@]3(C)C(C)(C)CCC(=O)[C@@]23C)[C@@H]1O</smiles>

14 $\alpha$-Hydroxyisopimara-7,15-dien-1-one (28)

Figure 4: Chemical structures of compounds 21-28

In addition, the presence of vicinal diol moiety as in $\mathbf{5}$ (two $\mathrm{OH}$ groups at $\mathrm{C}-7$ and $\mathrm{C}-6$ ) might also be critical to the vasorelaxant effect for the furanolabdane diterpenoids. The fascinating structures of hypophyllins will attract great interest for synthetic and biosynthetic communities. In addition, hypophyllins D (4) and E (5) also exhibited potent vasorelaxant activity, which made them promising lead compounds for the treatment of hypertension, heart disease, and stroke (Wu et al., 2016).

\section{Hypoestes triflora}

Puyvelde et al. (1989) stated that the $\mathrm{H}_{2} \mathrm{O}$ extract of $H$. triflora leaves prohibited the barbiturate sleeping time prolongation associated with carbon tetra chloride $\left(\mathrm{CCl}_{4}\right)$-induced liver damage in mice at dose $200 \mathrm{mg} / \mathrm{kg}$, compared to pentobarbital $(40 \mathrm{mg} / \mathrm{kg})$. This effect was due to benzoic acid. The isolated benzoic acid produced a significant reduction of the high levels of glutamate pyruvate transaminase (GPT) and glutamyl oxalacetate transaminases (GOT) induced by $\mathrm{CCl}_{4}$ administration (Puyvelde et al., 1989). 


\section{Hypoestes verticillaris}

Two phenanthroindolizidine alkaloids: hypoestestatins 1 (34) and 2 (35) have been separated from the East African $H$. verticillaris shrub. They possessed marked growth inhibitory potential towards murine lymphocytic leukemia (P-388) (ED $\left.5010^{-5} \mu \mathrm{g} / \mathrm{mL}\right)$ (Pettit et al., 1984).

\section{Hypoestes aristata}

In resazurin fluorescent assay, the leaves extract of $H$. aristata displayed cytotoxic potential towards human drug sensitive T-lymphoblastoid (CCRF-CEM) and multidrug-resistant T-lymphoblastoid (CEM/ADR5000) leukemia cells with $\mathrm{IC}_{50} \mathrm{~s} 2.28$ and $3.8 \mu \mathrm{g} / \mathrm{mL}$, respectively (Saeed et al., 2016).

\section{Hypoestes purpurea}

The separation and purification of the constituents obtained from the extract of $H$. purpurea aerial parts afforded furanolabdane diterpenes: hypopurins A-D (8-11), lignans: $\alpha$-O-methylcubebin (36), helioxanthin (38), hinoquinin (37), 7-hydroxyhinokinin (41), justicidine E (39), dehydroxycubebin (40), and (-)-hibalactone (42), and triterpenes: betulin (45) and lupeol (44) (Shen et al., 2004). Hypopurins A-D (8-11) were assessed for cyctotoxicity in vitro in 3-(4,5-dimethylthiazol-2-yl)-2,5-diphenyltetrazolium bromide (MTT) colorimetric assay towards the epidermoid carcinoma (KB) cell line. Hypopurin A (8) had moderate cytotoxic potential with an $\mathrm{IC}_{50} 9.4 \mu \mathrm{M}$, whereas, the other metabolites were inactive $\left(\mathrm{IC}_{50}>100 \mu \mathrm{M}\right)$ (Shen et al., 2004).

\section{Hypoestes serpens}

The isopimarane diterpenes: $14 \alpha$-hydroxyisopimara-7,15-dien-1-one (28), 7 $\beta$-hydroxyisopimara-8,15-dien-14-

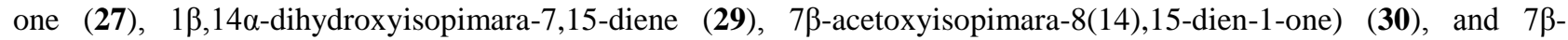
hydroxyisopimara-8(14),15-dien-1-one (31) were separated from $H$. serpens leaves. These metabolites were assessed for their antifungal potential towards Cladosporium cucumerinum and Candida albicans and acetylcholinesterase inhibitory activities (Rasoamiaranjanahary et al., 2003a). All compounds displayed antifungal activity against both plant pathogenic fungi: C. cucumerinum and C. albicans.<smiles>C=C[C@]1(C)CC[C@]2(C)C(=CC[C@H]3C(C)(C)CCC(O)[C@@]32C)[C@H]1O</smiles>

$1 \beta, 14 \alpha$-Dihydroxyisopimara-7,15-diene (29)<smiles>C=C[C@]1(C)C=C2[C@@H](O)C[C@H]3C(C)(C)CCC(=O)[C@@]3(C)[C@@H]2CC1</smiles>

7ß-Hydroxyisopimara-8(14),15-dien-1-one (31)<smiles>C=C[C@]1(C)C=C2[C@@H](OC)C[C@@]3(C)[C@]2(C)C(=O)CC[C@@]3(C)[C@@H](C)CC1</smiles>

$7 \beta$-Acetoxyisopimara-8(14),15-dien-1-one (30)

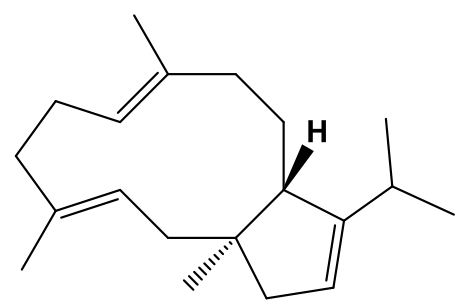

Dolabeserpenoic acid A (32) (3E,7Z)-Dollabella-3,7,12-trien-17-oic acid 
<smiles>C=C1C(=O)CC2C3CC(C)(CC4CC(C)(C[C@H](OC(C)=O)[C@@H]1C2(C)C)O4)O3</smiles>

Hypoestoxide (33)<smiles>COc1ccc2c(c1)-c1cc(OC)c(OC)cc1C1C2CN2CCCC2C1O</smiles><smiles>COc1ccc2c(c1)-c1cc(OC)c(OC)cc1C1CC3CCCN3CC21</smiles>

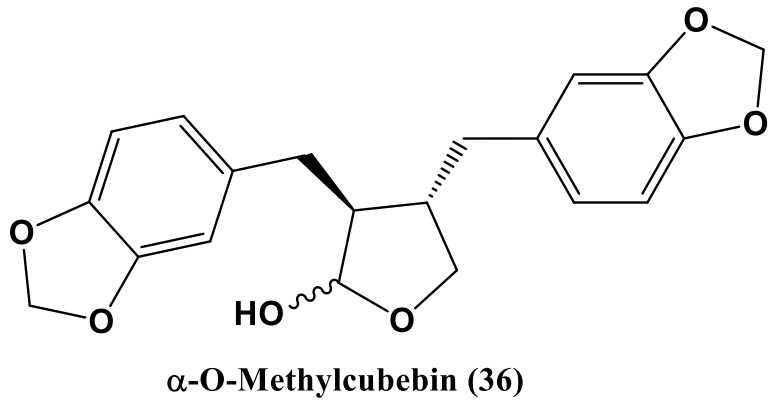

Figure 5: Chemical structures of compounds 29-36

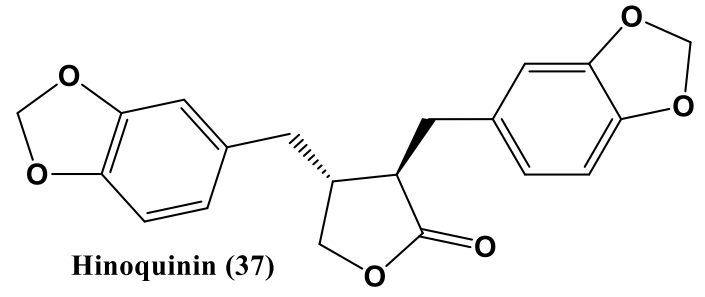

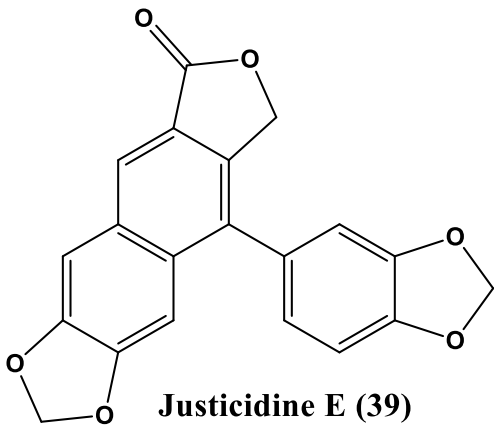<smiles>O=C1OC[C@H](Cc2ccc3c(c2)OCO3)/C1=C/c1ccc2c(c1)OCO2</smiles><smiles>C[As](C)(=O)c1ccc(-c2c3c(cc4ccc5c(c24)OCO5)C(=O)OC3)cc1OCO</smiles>
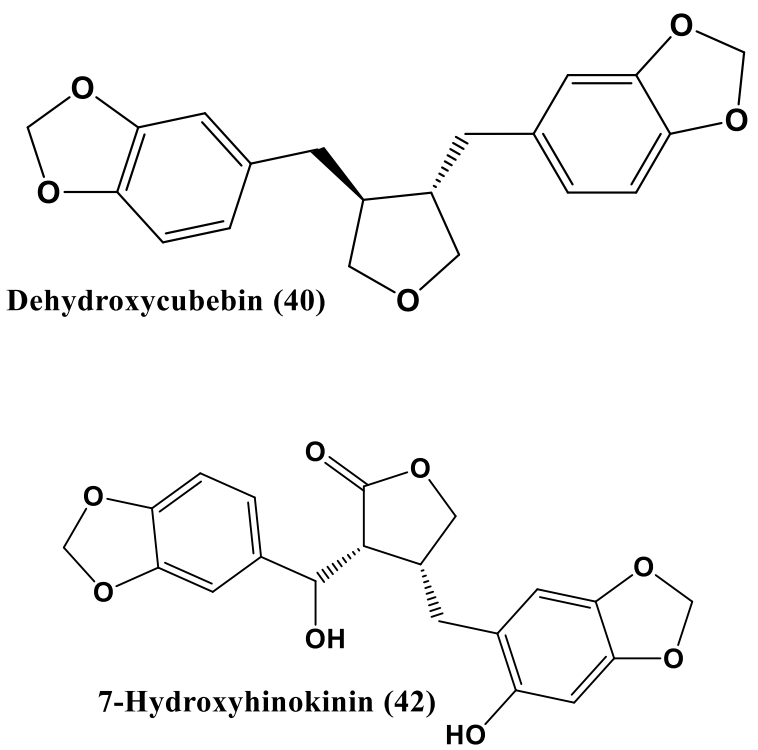
<smiles>c1cc2c(cc1[C@@H]1OC[C@H]3[C@H]1CO[C@H]3c1ccc3c(c1)OCO3)OCO2</smiles>

$(+)-S e s a m i n(43)$<smiles>C=C(C)[C@H]1CC[C@]2(C)CC[C@]3(C)C(CCC4[C@@]5(C)CC[C@@H](O)C(C)(C)C5CC[C@]43C)C12</smiles><smiles>C=C(C)[C@H]1CC[C@]2(C)CC[C@]3(C)C(CCC4[C@@]5(C)CC[C@H](O)C(C)(C)C5CC[C@]43C)C12</smiles><smiles>O=C(O)c1ccccc1</smiles>

Benzoic acid (46)

Figure 6: Chemical structures of compounds 37-46

Compounds 28 and $\mathbf{3 0}$ were the most potent compounds minimum inhibitory concentration (MIC) $0.5 \mu \mathrm{g}$ ) in the thin layer chromatography (TLC) bioautographic assay, compared to miconazole (MIC $1 \mu \mathrm{g}$ ). $7 \beta$ Hydroxyisopimara-8,15-dien-14-one (27) had the same MIC value as miconazole. The other compounds 29 and 30 were slightly active with MICs $25-50 \mu \mathrm{g}$ towards $C$. albicans and C. cucumerinum. As C. albicans is one of the causative agents of vaginitis. The inhibitory potential of these compounds towards $C$. albicans supported the use of $H$. serpens in traditional medicine to treat vaginitis. Moreover, $\mathbf{2 7}$ and $\mathbf{2 8}$ also exhibited acetylcholinesterase inhibitory potential. The MICs in a TLC bioautographic assay were determined as $0.5 \mu \mathrm{g}$ for $7 \beta$-hydroxyisopimara-8,15-dien-14one (27) and $0.2 \mu \mathrm{g}$ for 14 $\alpha$-hydroxyisopimara-7,15-dien-1-one (28) (Rasoamiaranjanahary et al., 2003a), compared to galanthamine alkaloid $(0.01 \mu \mathrm{g})$, which was introduced recently for treating Alzheimer's disease. Rasoamiaranjanahary et al. (2003b) reported the separation of dolabeserpenoic acid A (32) and fusicoserpenol A (26) with antifungal potential from $H$. serpens leaves. The MICs were 5 and $2 \mu \mathrm{g}$, respectively for $\mathbf{2 6}$ and $5 \mu \mathrm{g}$ for $\mathbf{3 2}$ towards both $C$. cucumerunum and C. albicans in the TLC bioautographic assay, compared to miconazole (MIC $1 \mu \mathrm{g}$ ) (Rasoamiaranjanahary et al., 2003b).

H. serpens alcohol extract afforded serpendione (16). The alcohol extract at concentrations $0.5,1$, and 1.5 $\mathrm{mg} / \mathrm{mL}$ had a good relaxant activity $\left(\mathrm{ED}_{50} 1.19 \mathrm{mg} / \mathrm{mL}\right)$ against contraction induced by noradrenaline with $7.50,19.55$, and $>100 \%$ reduction, respectively. Serpendione (concentration (Conc.) $0.05 \mathrm{mg} / \mathrm{mL}$ ) strongly repressed the maximal responses to the contractile agent with $92.2 \%$ inhibition. These results validate the utilization of $H$. serpens as a herbal medicine for treating hypertension (Andriamihaja et al., 2001).

\section{Hypoestes rosea}

Adesomoju et al. (1983a) purified hypoestoxide (HE, 33) from $H$. rosea leaves and twigs extracts (Adesomoju et al., 1983a). It frustrated IL-6, IL-1 $\beta$, and TNF- $\alpha$ production in lipopolysaccharide (LPS)-activated normal human peripheral blood mononuclear cells. Moreover, HE prohibited the nitric oxide (NO) production by interleukin-1 $\beta$ (IL$1 \beta$ ) or IL-17-stimulated normal human chondrocytes. HE oral administration to mice significantly ameliorated hind paw edema induced by antibodies to type II collagen plus LPS. Furthermore, its topical administration to mice also produced remarkable inhibition of ear inflammation induced by phorbol ester. The anti-inflammatory potential of HE may be due to its capacity to prohibit NF-kB activation through direct kappa-B kinase subunit alpha (IKK) inhibition. Thus, HE could have a significant effect in treating different inflammatory disorders and may represent a novel class of IKK inhibitors (Ojo-Amaize et al., 2001; Adesomoju 1983a).

It has been reported that HE inhibited mouse melanoma $(\mathrm{B} 16 \mathrm{~F} 1)$ in the tumor model C57BL/6 mice. OjoAmaize et al. (2007a) demonstrated that mean tumors volumes in mice treated with HE orally alone or combined with 5-fluorouracil (5-FU) were significantly smaller (> 60\%) than those in control mice $\left(471.2 \mathrm{~mm}^{3} \mathrm{vs} 1542.8 \mathrm{~mm}^{3}\right)$ in the in ovo chick chorioallantoic membrane (CAM) assay. The remarkable reductions in tumor led to increase in life spans (ILS) and prominent survival times mean (STM) in the treated mice. These results indicated that HE is an efficient anticancer agent for colorectal cancer (CT26.WT) alone or in combination with 5-FU (Ojo-Amaize et al., 2007a). The tumor inhibitory action of $\mathrm{HE}$ is due to its capability to arrest cell cycle at $\mathrm{G}_{2}-\mathrm{M}$ phase by the interfering with actin assembly, inhibiting angiogenesis, migration of the endothelial cell, and vascular endothelial growth factor (VEGF)induced cell proliferation (Flis et al., 2006). In contrast, 5-FU triggered apoptosis by depleting thymidine through direct incorporation into deoxyribonucleic acid (DNA) and ribonucleic acid (RNA) and thymidine synthase inhibition (Wada et al., 2006). Low doses combination of 5-FU and HE enhanced the 5-FU anti-tumor responses Ojo-Amaize et al., 
2001; 2002). Interestingly, the consumption of the dried leaf powder of $H$. rosea as a supplement led to the removal of the existing intestinal polyps in human (Ojo-Amaize et al., 2007a). Also, HE inhibited the in vitro growth of various murine and human tumor cell lines at concentrations 0.3 to $10 \mu \mathrm{M}$. Also, it was inactive in the Ames test as a mutagen. HE possessed a strong potency (Conc. $0.3-10 \mathrm{mg} / \mathrm{kg}$ ) towards P-388D1 leukemia in C57BL/6 $\times$ DBA/2 $\mathrm{F}_{1}$ and mouse melanoma (B16) cell growth in C57BL/6 mice. At a low maximal effective dose of $5 \mathrm{mg} / \mathrm{kg}$, HE had a promising in vivo antitumor potential that was comparable with or better than cortisone acetate, bleomycin, vincristine, 5fluorouracil, adriamycin, etoposide, and cyclophosphamide. HE prohibited the HeLa (cervical epitheloid carcinoma) and human Burkitt lymphoma (CA46) cells growth in the cell cycle G2-M phase, which caused either indirect or direct interference with actin assembly. Thus, the arrest in the cell cycle took place at cytokinesis as observed by the increase in binucleate cells number. Moreover, HE prohibited in vitro vascular endothelial growth factor-induced cell proliferation with an $\mathrm{IC}_{50} 28.6 \mu \mathrm{M}$ and significantly inhibited basic fibroblast growth factor-induced angiogenesis on the chick chorioallantoic membrane with an $\mathrm{IC}_{50} 10 \mu \mathrm{M}$. Furthermore, HE inhibited migration of endothelial cells on collagen, vitronectin, and fibronectin (Ojo-Amaize et al., 2002). Ojo-Amaize et al., (2007b) stated that HE had a relatively weak in vitro activity with $\mathrm{IC}_{50} 10 \mu \mathrm{M}$, compared to chloroquine $\mathrm{IC}_{50} 0.11 \mu \mathrm{M}$ towards various strains of $P$. falciparum. The suppressive dose $\left(\mathrm{SD}_{90}\right)$ of $\mathrm{HE}\left(\mathrm{SD}_{90} 250 \mu \mathrm{g} / \mathrm{kg}\right)$ is much lower than chloroquine $\left(\mathrm{SD}_{90} 5 \mathrm{mg} / \mathrm{kg}\right)(\mathrm{Ojo}-$ Amaize et al., 2007b). It was speculated that the $\alpha, \beta$-unsaturated ketone substructure of HE may interfere with the parasite mitochondrial electron transport as in $\beta$-methoxyacrylates (Ojo-Amaize et al., 2007b; Alzeer et al., 2000). HE inhibited the sporozoites motility and endothelial cell migration, also interfered with cytokinesis and actin assembly (Ojo-Amaize et al., 2007b; Tardieux et al., 1998).

\section{Conclusion}

This works provides a background for the future studies on Hypoestes species, particularly the species, which have not been extensively explored for separation and characterization of bioactive constituents and pharmacological potentials. Further investigations of these species are guaranteed to identify the bioactive metabolites responsible for diverse pharmacological and biological effects.

Conflict of interest: I confirm that there are no known conflicts of interest associated with this publication and there has been no significant financial support for this work that could have influenced its outcome.

\section{References}

1. Adesomoju, A.A., Okogun, J.I., Cava, M.P. and Carroll, P.J. (1983a). Hypoestoxide, a new diterpene from Hypoestes rosea (Acanthaceae). Heterocycles 20:925 -2128.

2. Adesomoju, A.A., Okogun, J.I., Cava, M.P. and Carroll, P.J. (1983b). Roseadione, A diterpene ketone from Hypoestes rosea. Phytochemistry 22:2535-2536.

3. Al Musayeib, N.M., Mothana, R.A., Mohamed, G.A., Ibrahim, S.R.M. and Maes, L. (2014). Hypoestenonols A and B, new fusicoccane diterpenes from Hypoestes forskalei. Phytochemistry Letters 10:23-27.

4. Almehdar, H., Abdallah, H.M., Osman, A.M. and Abdel-Sattar, E.A. (2012). In vitro cytotoxic screening of selected Saudi medicinal plants. Journal of Natural Medicines 66:406-412.

5. Al-Rehaily, A.J., Al-Yahya, M.A., Mirza, H.H. and Ahmed, B. (2002). Verticillarone: A new secofusicoccane diterpenoid ketonepoxide from Hypoestes verticillaris. Journal of Asian Natural Products Research 4:117-122.

6. Alzeer, J., Chollet, J., Heinze-Krauas, I., Huberchwerlen, C., Matile, H. and Ridley, R.G. (2000) Phenyl $\beta$ Methoxyacrylates: a new antimalarial pharmacophore. Journal of Medicinal Chemistry 43:560-565.

7. Andriamihaja B, Martin M-T, Rasoanaivo P, Frappier F. (2001). A New Diterpene from Hypoestes serpens. Journal of Natural Products 64:217-218.

8. Bhat, R.B. (2014). Medicinal plants and traditional practices of Xhosa people in the Transkei region of Eastern Cape, South Africa. Indian Journal of Traditional Knowledge 13: 292-298.

9. Darbyshire, I. (2015). The genus Hypoestes (Acanthaceae) in Angola. Kew Bulletin 70: 44.

10. Flis, S., Soltysiak-Pawluczuk, D., Jedrych, A., Jastrzebski, Z., Remiszewska, M. and Splawinski, J. (2006). Antiangiogenic effect of sulindac sulfide could be secondary to induction of apoptosis and cell cycle arrest. Anticancer Research 26: 3033-3041.

11. Fongod, A.G.N., Modjenpa, N.B. and Veranso, MC. (2013). Ethnobotany of Acanthaceae in the Mount Cameroon region. Journal of Medicinal Plants Research 7:2707-2713.

12. Iwu, M.M. (1993). Handbook of African Medicinal Plants. CRC Press, Florida.

13. Kipkore W, Wanjohi B, Rono H, Kigen G. (2014). A study of the medicinal plants used by the Marakwet community in Kenya. Journal of Ethnobiology and Etthnomedicine 10:24.

14. Mabberley, D.J. (2008). Mabberley's Plant-Book. Third Edition. Cambridge University Press.

15. Mothana, R.A., Al-Musayeib, N.M., Al-Ajmi, M.F., Cos, P. and Maes L. (2014). Evaluation of the in vitro antiplasmodial, antileishmanial, and antitrypanosomal activity of medicinal plants used in Saudi and Yemeni traditional medicine. Evidence- Based Complementary and Alternative Medicine 2014. Article ID 905639, 7 pages. 
16. Mothana, R.A., Lindequist, U., Gruenert, R. and Bednarski, P.J. (2009). Studies of the in vitro anticancer, antimicrobial and antioxidant potentials of selected Yemeni medicinal plants from the island Soqotra. BMC Complementary and Alternative Medicine 9:7 doi:10.1186/1472-6882-9-7.

17. Mothana, R.A.A., Kriegisch, S., Harms, M., Wende, K. and Lindequist, U. (2011). Assessment of selected Yemeni medicinal plants for their in vitro antimicrobial, anticancer, and antioxidant activities. Pharmaceutical Biology 49:200-210.

18. Muhammad, I., Mossa, J.S., Al-Yahya, M.A., El-Ferdly, F.S. and McPhail AT. (1997). Hypoestenone: a fusicoccane diterpene ketone from Hypoestes forskalei. Phytochemistry 44:125-129.

19. Muhammad, I., Mossa, J.S., Ramadan, A.F., Farouk, El-feraly S. and Hufford, C.D. (1998). Additional diterpene ketones from Hypoestes forskalei. Phytochemistry 47: 1331-1336.

20. Mukazayire, M-J, Minani, V., Ruffo, C.K., Bizuru, E., Stévigny, C. and Duez, P. (2011). Traditional phytotherapy remedies used in Southern Rwanda for the treatment of liver diseases. Journal of Ethnopharmacology 138:415-431.

21. Muthaura, C.N., Keriko, J.M., Mutai, C., Yenesew, A., Gathirwa, J.W., Irungu, B.N., Nyangacha, R., Mungai, G.M. and Derese, S. (2015). Antiplasmodial potential of traditional phytotherapy of some remedies used in treatment of malaria in Meru-Tharaka Nithi County of Kenya. Journal of Ethnopharmacology 175:315-323.

22. Ojo-Amaize, E.A., Cottam, H.B., Oyemade, O.A., Okogun, J.I. and Nchekwube, E.J. (2007a). Hypoestoxide inhibits tumor growth in the mouse CT26 colon tumor model. World Journal of Gastroenterology 14:4586-4588.

23. Ojo-Amaize, E.A., Kapahi, P., Kakkanaiah, V.N., Takahashi, T., Shalom-Barak, T., Cottam, H.B., Adesomoju, A.A., Nchekwube, E.J., Oyemade, O.A., Karin, M. and Okogun JI. (2001). Hypoestoxide, a novel anti-inflammatory natural diterpene, inhibits the activity of IkB kinase. Cellular Immunology 209:149-157.

24. Ojo-Amaize EA, Nchekwube EJ, Cottam HB, Bai R, Verdier-Pinard P, Kakkanaiah VN, Varner JA, Leoni L, Okogun JI, Adesomoju AA, Oyemade OA, Hamel E. (2002). Hypoestoxide, a natural nonmutagenic diterpenoid with antiangiogenic and antitumor activity: possible mechanisms of action. Cancer Research 62:4007-4014.

25. Ojo-Amaize EA, Nchekwube EJ, Cottam HB, Oyemade OA, Adesomoju AA, Okogun JI. (2007b). Plasmodium berghei: antiparasitic effects of orally administered hypoestoxide in mice. Experimental Parasitology 117:218-221.

26. Okogun, J.I., Adesomoju, A.A., Adesida, G.A., Lindner, H.J. and Habermehl, G. (1982). Roseanolone: A new diterpene from Hypoestes rosea Z. Naturforsch. 37c:558-561.

27. Pettit, G., Goswami, A., Cragg, G.M., Schmidt, J.M. and Zou, J-C. (1984). Antineoplastic agents, 103. The isolation and structure of hypoestestatins 1 and 2 from the east African Hypoestes verticillaris. Journal of Natural Products 47: 913-919.

28. Puyvelde, L.V., Kayonga, A., Brioen, P., Costa, J., Ndimubakunzi, A., Kimpe, N.D. and Schamp, N. (1989). The hepatoprotective principle of Hypoestes Triflora leaves. Journal of Ethnopharmacology 26:121-127.

29. Rasoamiaranjanahary L, Guilet D, Marston A, Randimbivololona F, Hostettmann K. (2003a). Antifungal isopimaranes from Hypoestes serpens Phytochemistry 64:543-548.

30. Rasoamiaranjanahary, L., Marston, A., Guilet, D., Schenk, K., Randimbivololona, F. and Hostettmann, K. (2003b). Antifungal diterpenes from Hypoestes serpens (Acanthaceae). Phytochemistry 62:333-337.

31. Saeed, M.E.M., Meyer, M., Hussein, A. and Efferth, T. (2016). Cytotoxicity of South-African medicinal plants towards sensitive and multidrug-resistant cancer cells. Journal of Ethnopharmacology 186:209-223.

32. Scotland, R.W. and Vollesen, K. (2000). Classification of Acanthaceae. Kew Bulletin 5:513-580.

33. Shen, C-C., Ni, C-L, Huang, Y-L., Huang, R-L. and Chen C-C. (2004) Furanolabdane Diterpenes from Hypoestes purpurea. Journal of Natural Products 67:1947-9.

34. Tardieux, I., Liu, X., Poupel, O., Parzy, D., Dehoux, P. and Lansley, G.A. (1998) Plasmodium falciparum novel gene encoding a coronin-like protein which associates with actin filaments. FEBS Letters 441:251-6.

35. Teklay, A., Abera, B., Giday, M. (2013). An ethnobotanical study of medicinal plants used in Kilte Awulaelo District, Tigray Region of Ethiopia. Journal of Ethnobiology and Ethnomedicine 9:65.

36. Theplantlist. (2013). http://www.theplantlist.org/tpl1.1/search?q=hypoestes accessed 20/10/2017.

37. Ubaha GA, Idowu BA, Omoniyi IT. (2012). Effects of Hypoestes forskalei Schult Roem leaf extract on the behavior of Clarias gariepinus. Journal of Natural Science 10:158-162.

38. Wada, Y., Yoshida, K., Suzuki, T., Mizuiri, H., Konishi, K., Ukon, K., Tanabe, K., Sakata, Y. and Fukushima M. (2006). Synergistic effects of docetaxel and S-1 by modulating the expression of metabolic enzymes of 5fluorouracil in human gastric cancer cell lines. International Journal of Cancer 119:783-91.

39. Wu, X-D., Luo, D., Tu, W-C., Deng, Z-T., Chen, X-J., Su, J., Ji, X. and Zhao, Q-S. (2016). Hypophyllins AD, labdane-type diterpenoids with vasorelaxant activity from Hypoestes phyllostachya "Rosea". Organic Letters 18:6484-7.

40. Zhang, X. (2004). Traditional medicine: Its importance and protection. In: Twarog S, Kapoor P, eds. Protecting and Promoting Traditional Knowledge: Systems, National Experiences and International Dimensions. Part 1. The Role of Traditional Knowledge in Healthcare and Agriculture. New York: Aristolochia contorta United Nations 3-6. 